\title{
Neurofibromin is a Novel Regulator of Ras-induced Reactive Oxygen Species Production in Mice and Humans
}

Waylan K. Besslert $\dagger^{\mathrm{a}, \mathrm{b}, \mathrm{c}}$, Farlyn Z. Hudson ${ }^{\mathrm{d}, \mathrm{e}}$, Hanfang Zhang ${ }^{\mathrm{d}, \mathrm{e}}$, Valerie Harris ${ }^{\mathrm{d}, \mathrm{e}}$,Yusi Wang ${ }^{\mathrm{e}, \mathrm{f}}$, Julie A. Mund ${ }^{a, b, g}$, Brandon Downing ${ }^{a, b}$,David A. Ingram, Jr, ${ }^{a, b, c}$, Jamie Case $^{a, g, h}$, David J. Fulton ${ }^{\mathrm{e}, \mathrm{f}}$, and ${ }^{*}$ Brian K. Stansfield ${ }^{\mathrm{d}, \mathrm{e}}$

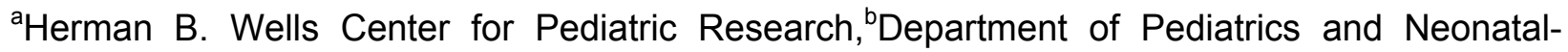
Perinatal Medicine, and ${ }^{\mathrm{C}}$ Department of Biochemistry and Molecular Biology, Indiana University School of Medicine, Indianapolis 46202.

${ }^{\mathrm{d}}$ Department of Pediatrics and Neonatal-Perinatal Medicine, and 'Vascular Biology Center, fDepartment of Pharmacology and Toxicology,Augusta University, Augusta, GA 30912

${ }^{9}$ Melvin and Bren Simon Cancer Center,Indiana University School of Medicine, Indianapolis 46202

${ }^{\text {h }}$ Scripps Clinic Medical Group, Center for Organ and Cell Transplantation, La Jolla, CA 92037

† W.B. and F.H. contributed equally to this work.

${ }^{*}$ Corresponding Author

Brian K. Stansfield, M.D.

Department of Pediatrics, Augusta University

$112015^{\text {th }}$ St, BIW 6033, Augusta, GA 30912

Phone: 706.721.2331; Fax: 706.721.7531

E-mail: bstansfield@gru.edu

Word Count: Total Figures: 


\section{Abstract:}

Neurofibromatosis type 1 (NF1) predisposes individuals to early and debilitating cardiovascular disease. Loss of function mutations in the NF1 tumor suppressor gene, which encodes the protein neurofibromin, leads to accelerated p2 $1^{\text {Ras }}$ activity and phosphorylation of multiple downstream kinases, including Erk and Akt. Nf1 heterozygous $\left(N f 1^{+/}\right)$mice develop a robust neointima that mimics human disease. Monocytes/macrophages play a central role in NF1 arterial stenosis as Nf1 mutations in myeloid cells alone are sufficient to reproduce the enhanced neointima observed in $\mathrm{Nf}^{+/-}$mice. Though the molecular mechanisms underlying NF1 arterial stenosis remain elusive, macrophages are important producers of reactive oxygen species (ROS) and Ras activity directly regulates ROS production. Here, we use compound mutant and lineage-restricted mice to demonstrate that $\mathrm{Nf}^{+/-}$macrophages produce excessive ROS, which enhanceNf1 ${ }^{+/}$smooth muscle cell proliferationin vitro and in vivo. Further, use of a specific NADPH oxidase-2 inhibitor to limit ROS production prevents neointima formation in $\mathrm{Nf}^{+/-}$mice. Finally, mononuclear cells from asymptomatic NF1 patients have increased oxidative DNA damage, an indicator of chronic exposure to oxidative stress. These data provide genetic and pharmacologic evidence that excessive exposure to oxidant species underlie NF1 arterial stenosis and provide a platform for designing novels therapies and interventions.

Key words: Neurofibromatosis, neointima, arterial stenosis, reactive oxygen species, macrophage, monocyte, smooth muscle cell, superoxide, NADPH oxidase, apocynin, Ras 


\section{Abbreviations}

\begin{tabular}{|c|c|}
\hline EEL & External elastic lamina \\
\hline IEL & Internal elastic lamina \\
\hline I/M Ratio & Intima/Media ratio \\
\hline MNC & Peripheral blood mononuclear cells \\
\hline NF1 & Neurofibromatosis type 1 \\
\hline $\mathrm{Nf1}^{+/-}$ & Heterozygous for the $N f 1$ allele \\
\hline$N f 1^{+/-} ; p 47^{--}$ & $\begin{array}{l}\text { Heterozygous for the Nf1 allele and homozygous deletion of } \\
\qquad 47^{\text {phox }}\end{array}$ \\
\hline$N f 1^{\text {flox/+ } ; L y s M^{\text {cre }}}$ & Heterozygous for the $N f 1$ allele in myeloid cells alone \\
\hline$N f 1^{\text {flox/flox }} ; L y s M^{\text {cre }}$ & Homozygous for the $N f 1$ allele in myeloid cells alone \\
\hline$N f^{\text {lox } /+} ; g p 91^{\text {flox/flox }} ;$ LysMcre & $\begin{array}{l}\text { Heterozygous for the Nf1 allele and homozygous deletion of } \\
\text { gp } 91^{\text {phox }} \text { in myeloid cells alone }\end{array}$ \\
\hline NOX2 & NADPH oxidase 2 \\
\hline PMA & Phorbol myristate acid \\
\hline Ras & p21 Ras pathway \\
\hline ROS & Reactive oxygen species \\
\hline SMC & Smooth muscle cell \\
\hline SOD & Superoxide dismutase \\
\hline WT & Wild type \\
\hline
\end{tabular}




\section{Introduction}

Neurofibromatosis type 1 (NF1) is a common genetic disorder resulting from germline mutations in the NF1 tumor suppressor gene and affects over 2 million people worldwide(1). Neurofibromin, the protein product of NF1, functions as a catalyst for the slow, intrinsic hydrolysis of active p21 Ras $($ Ras)(1). Thus, loss of neurofibromin expression increases Rasdependent kinase activity in response to growth factor stimulation of receptor tyrosine kinases. The downstream Ras kinases Erk and Akt turn on multiple molecular switches to promote a pro-survival phenotype in neurofibromin-deficient cells.

Persons with NF1 have a strong predisposition for cardiovascular disease, which often presents in adolescence and early adulthood(2-4). Upwards of $8 \%$ of NF1 patients will develop hypertension, arterial stenosis, aortic aneurysms, or moya moya, though universal screening has not been adopted and may underestimate the true prevalence of disease(4-6). The distribution of NF1 vasculopathy within a single patient is often patchy and affects multiple vessels(4). The varied presentation of arterial lesions suggests that NF1 patients may require a "second hit" mutation in the normal NF1 allele or, more likely, a local insult in the vessel wall leading to dysregulation of normal repair mechanisms. Constitutional homozygosity for NF1 mutations is embryonic lethal in humans and mice; therefore, inherited mutations in a single NF1 allele are likely sufficient for the increased disease prevalence and provide a platform for investigation(7).

We have developed a mouse model of NF1 arterial stenosis using Nf1 heterozygous $\left(\mathrm{Nf1}^{+/}\right)$mice that phenotypically resembles human NF1 arterial lesions(8-12). Following carotid artery injury, $\mathrm{Nf1}^{+-}$mice develop a robust neointima when compared with WT mice, which is characterized by a-SMA positive smooth muscle cells (SMC) and a predominance of bone marrow-derived macrophages within the neointima(10-12). Disruption of PDGF-Ras-Erk signaling inhibits $\mathrm{Nf1}^{+/-} \mathrm{SMC}$ proliferation and prevents neointima formation in $\mathrm{Nf1}^{+/-}$mice(9); however, SMC-specific $N f 1$ heterozygosity failed to replicate the enhanced neointima observed 
in $\mathrm{Nf}^{+/-}$mice and provides evidence that other cell populations arerequired to initiate neointima formation in $\mathrm{Nf}^{+/-}$mice $(8,10)$. In support of this hypothesis, WT mice reconstituted with $\mathrm{Nf1}{ }^{+/}$ bone marrow developed a pronounced neointima following carotid artery ligation while $\mathrm{Nf}^{+/-}$ mice reconstituted with WT bone marrow developed a modest neointima similar in size to WT lesions(8). Further, we recently showed that loss of a single Nf1 gene copy in myeloid cells is sufficient to reproduce the exaggerated arterial lesions observed in $N f 1^{+/}$mice(11). These experiments in lineage-restricted and chimeric mice provide strong evidence that neurofibromindeficient monocytes and macrophages are critical mediators of $\mathrm{Nf}^{+/-}$arterial stenosis. However, the mechanisms through which $\mathrm{Nf}^{+/-}$monocytes and macrophages directly influence $\mathrm{Nf1}{ }^{+/}$ SMC proliferation and arterial stenosis is completely unknown.

Emerging evidence suggests that Ras kinases directly regulate reactive oxygen species (ROS) production and, in turn, ROS may modulate Ras activity(13-15). Constitutive activation of Ras in hematopoietic progenitor and cancer cells dramatically increases ROS production via activation of the NADPH oxidase complex(16-19). Also, Drosophila harboring mutations in the Nf1 gene exhibited shortened lifespan and increased production of and vulnerability to ROS(20, 21), while overexpression of neurofibromin prolonged lifespan and reduced ROS production(22). More recently, neurofibromin deficiency or Ras activationsignificantly increased oligodendrocyte ROS productionand disrupted endothelial tight junctions, which was restored by daily administration of the antioxidant $\mathrm{N}$-acetyl cysteine(23). These findings are intriguing since neurofibromin occupies a unique position in the regulation of kinases that activate ROS production and enhance SMC proliferation(24-26). For example, the Ras-dependent kinases Akt and Erk directly phosphorylate the $\mathrm{p} 47^{\text {phox }}$ subunit of NADPH oxidase 2 (NOX2) and facilitate Rac2-dependent recruitment of $p 67^{\text {phox }}$ to the transmembrane component of NOX2 to increase superoxide production in phagocytes(27-29). Overproduction of ROS in infiltrating leukocytes via NOX2 therefore may augment SMC function and participate in the pathogenesis of arterial lesions in NF1 patients. Therefore, we hypothesize that loss of neurofibromin in 
monocytes/macrophages enhances ROS production via NOX2 activation and amplifies $N f 1^{+/}$ SMC proliferation leading to occlusive arterial disease. As a corollary to our experimental murine work, we seek to identify whether NF1 patients experience chronic oxidative stress.

\section{Materials and Methods}

\section{Animals}

Protocols were approved by Laboratory Animal Services at Augusta University and Indiana University. $\mathrm{Nf1}^{+-}$mice were obtained from Tyler Jacks (Massachusetts Institute of Technology, Cambridge, MA) and backcrossed 13 generations into the C57BL/6J strain. $p 47^{\text {phox }}(4742)$ knockout mice $\left(p 47^{-/}\right)$were purchased from The Jackson Laboratory and maintained on $\mathrm{C} 57 \mathrm{BL} / 6$ strain. $\mathrm{Nf1^{+/ }}$ mice were intercrossed with $\mathrm{p} 47^{-/}$mice to produce $\mathrm{Nf} 1^{+/-}$ $; p 47^{-/}$mice. Nf1 $1^{\text {floxflox }}$ mice were obtained from Luis Parada (University of Texas Southwestern Medical Center, Dallas, TX) and maintained on C57BL/6 background. gp9 floxflox mice were obtained from Abay Shah (King's College, London, UK). LysMcre (4781)mice were purchased from The Jackson Laboratory and maintained on C57BL/6 background. Nf1 ${ }^{\text {flox/lox }}$ mice were crossed with $g p 91^{\text {flox/flox }}$ and LysMcre mice to generate $N f^{f l o x /+} ;$ gp $91^{\text {flox/flox }} ;$ LysMcre mice (heterozygous loss of $N f 1$ and homozygous loss of $g p 91^{\text {phox }}$ in myeloid cells only). LysM is expressed in neutrophils and macrophages. Cre-mediated recombination was confirmed by PCR as previously described(11). Inbreeding of $N f 1^{\text {floxflox }}$ mice with LysMcre mice yielded $N f 1^{f l o x /+} ;$ LysMcre (heterozygous loss of $\mathrm{Nf1}$ in myeloid cells alone) and $N f 1^{f l o x /+}$ (WT) controls. Male mice, between 12 and 15 weeks of age, were used for experiments.

\section{Carotid artery ligation}

Carotid artery injury was induced by ligation of the right common carotid artery as previously described(11). Briefly, mice were anesthetized by inhalation of an isoflurane (2\%)/oxygen (98\%) mixture. Under a dissecting scope, the right carotid artery was exposed 
through a midline neck incision and ligated proximal to the bifurcation using a 6-0 silk suture. The contralateral carotid artery was sham ligated as a control. Mice were administered $15 \mu \mathrm{g}$ of buprenorphine (IP) following the procedure and recovered for 28 days. Whole ligated and control arteries were harvested from experimental mice for analysis as previously described.

\section{Morphometric analysis}

Van Gieson-stained arterial cross sections 400,800 , and $1,200 \mu \mathrm{m}$ proximal to the ligation were analyzed for neointima formation using Image $\mathrm{J}(\mathrm{NIH}$, Bethesda, MD). Lumen area, area inside the internal elastic lamina (IEL), and area inside the external elastic lamina (EEL) were measured for each cross section. To account for potential thrombus formation, arteries containing significant thrombus ( $>50 \%$ lumen occlusion) at $400 \mu \mathrm{m}$ proximal to the ligation were excluded from analysis. The number of excluded arteries was not different between experimental groups. Representative photomicrographs for each figure are taken from arterial cross sections between 600 and $1200 \mu$ m proximal to the bifurcation. Intima area was calculated by subtracting the lumen area from the IEL area, and the media area was calculated by subtracting the IEL area from the EEL area. Intima/Media (I/M) ratio was calculated as intima area divided by media area.

\section{Arterial ROS detection in vivo}

Carotid arteries from $\mathrm{Nf1}^{+/-}$and WT mice were injured as described above. Forty-eight hours after injury, dihydroethidium $(20 \mathrm{mg} / \mathrm{kg})$ was provided via IP injection. After an additional 24-hour recovery period, mice were sacrificed and whole control and injured carotid arteries were perfused with heparinized saline and flash frozen in OCT compound. Arterial cross sections $(20 \mu \mathrm{m})$ were analyzed for fluorescence using an EVOS FL microscope. In a second set

of experiments, whole arteries from $\mathrm{Nf1}^{+/}$and WT micewere harvested 72 hours after injury and 
pooled, minced into a single cell suspension, and placed in boiling sodium dodecyl sulfate (SDS) buffer. NOX2 and $\beta$-actin expression were analyzed by western blot.

Isolation of bone marrow-derived macrophages, characterization, and ROS determination Bone marrow-derived macrophage isolation and characterization was performed as described(8). To assess ROS production, WT, Nf1 ${ }^{\text {flox/+ }} ;$ LysMcre, and $N f 1^{\text {flox/flox }}$ :LysMcre macrophages $\left(5 \times 10^{5}\right.$ cells) were suspended in $0.5 \mathrm{~mL}$ Hank's Balanced Salt Solution (HBSSS)

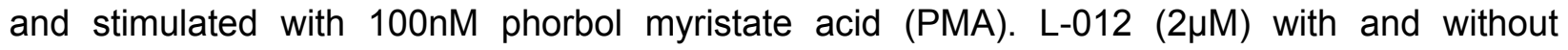
50units/mL superoxide dismutase (SOD) was added to the suspension and luminescence was measured at 15 -second intervals in a luminometer. In some experiments, macrophages were incubated with PD0325901 (10nM) or wortmannin (50nM) to specifically inhibit Erk and Akt activity, respectively. All experiments were performed in triplicate in four distinct cohorts.

\section{Smooth muscle cell isolation and proliferation}

Smooth muscle cell isolation and proliferation assays were performed as described(26). SMC were obtained by outgrowth from explants of WT and $\mathrm{Nf1}^{+/-}$thoracic aortas. SMC were cultured in DMEM supplemented with $20 \%$ fetal bovine serum and $100 \mathrm{U} / \mathrm{ml}$ penicillin/streptomycin in a $37^{\circ} \mathrm{C}, 5 \% \mathrm{CO}_{2}$-humidified incubator. For cell proliferation, SMC $\left(5,000\right.$ cells $\left./ \mathrm{cm}^{2}\right)$ were placed in a 96 -well plate and deprived of growth factors for 12-18 hours. Quiescent SMC were stimulated with $\mathrm{H}_{2} \mathrm{O}_{2}(1$ and $100 \mu \mathrm{M})$ for 24 hours and pulse-labeled with 1 $\mu \mathrm{Ci} / \mathrm{ml}$ of $\left[{ }^{3} \mathrm{H}\right]$ thymidine for $6 \mathrm{~h}$. $\beta$ emission was measured and reported as counts per minute. Cell counts using a hemocytometer were performed to confirm radioisotope results. Under the same conditions, cell viability was assessed by MTT assay and light absorbance was measured using a plate reader $(570 \mathrm{~nm})$. All experiments were performed in triplicate in four distinct cohorts. 


\section{Patient Recruitment}

NF1 patients were recruited by the Indiana University NF1 Clinic at Riley Hospital for Children. All patients received a physical examination and a medical history was taken to confirm the diagnosis of NF1 according to the NIH clinical criteria(30). Patients with a history of cancer, on anti-cancer drugs or pregnant were excluded from the study. All patients gave informed consent prior to participation in the study.

\section{Isolation of Human Peripheral Blood Mononuclear Cells and Analysis}

Blood samples were collected from NF1 patients (37.6 \pm 9.7 years) and age- and sex-matched healthy controls (40.2 \pm 8.1 years) into EDTA Vacutainer tubes (BD Biosciences). Peripheral blood mononuclear cells (MNCs) were isolated from $16 \mathrm{ml}$ of peripheral blood by density centrifugation using Ficoll-Paque Plus (GE Healthcare) as previously described(31). A total of 1 $\times 10^{6}$ MNCs were resuspended in PBS with $2 \%$ FBS and incubated with human FcR Blocking Reagent (Miltenyi Biotec) for 10 minutes at $4^{\circ} \mathrm{C}$. After blocking, MNCs were incubated for 30 minutes at $4^{\circ} \mathrm{C}$ with the following primary conjugated monoclonal antibodies: anti-human CD14-PECy5.5 (Abcam), anti-human CD45-allophycocyanin-Alexa Fluor 750 (Invitrogen), and anti-human CD16-PECy7 (BD Biosciences — Pharmingen), as well as the live/dead marker ViVid (Invitrogen). After staining, MNCs were washed 2 times with PBS with $2 \%$ FBS and fixed in $1 \%$ formaldehyde (Sigma-Aldrich) for a minimum of 24 hours. Stained MNC samples were acquired on a BD LSRII flow cytometer equipped with a 405-nm violet laser, 488-nm blue laser, and 633-nm red laser. At least 300,000 events were collected for each sample. Data were collected uncompensated and analyzed using FlowJo software version 8.7.3 (Tree Star).

\section{Modified Comet Assay in Human Mononuclear Cells}

MNCs were assayed for oxidative DNA damage as previously described, with modification(32). Following cell lysis, slides were treated with formamidopyrimidine DNA glycosylase (FPG), 
which recognized and removed oxidized purines, causing a DNA break. For each sample, 100 cells were analyzed. The Institutional Review Board of the Indiana University School of Medicine approved all protocols using human tissue samples.

\section{Statistics}

All values are presented as mean \pm S.E.M. unless otherwise noted. Human monocyte frequency and leukocyte oxidative-DNA damage was analyzed using Student's $t$-test and sample distribution was analyzed by F-test. Macrophage ROS production and SMC proliferation and viability was analyzed using 2-way ANOVA with Tukey's post-hoc test for multiple comparisons. Intima area and I/M ratio analysis was assessed by 1-way ANOVA with Tukey's post-hoc test for multiple comparisons. Murine experiments using apocynin treatment were assessed using 2-way ANOVA with Tukey's post-hoc test for multiple comparisons. Analysis was performed using GraphPad Prism version 5.0d. $P<0.05$ were considered significant.

\section{Results}

Neurofibromin-deficient macrophages produce excessive superoxide via p21 Ras activation.

The $\mathrm{p} 21^{\text {Ras }}$ pathway directly, but not completely, regulates intracellular and extracellular oxidant species concentration; therefore, Ras activation in neurofibromin-deficient leukocytes may increase ROS production. To examine the role of neurofibromin-deficiency in leukocytemediated ROS production, we utilized cre/lox technology to isolate Nf1 heterozygous and homozygous macrophages. As Nf1 nulzygosity results in embryonic lethality, we isolated bone marrow macrophages from $N f 1^{f l o x /+} ; L y s M^{\text {cre }}$ ( $N f 1$ heterozygous in myeloid cells) and $N f 1^{\text {flox/flox }}$;LysM ${ }^{\text {cre }}$ (Nf1 homozygous in myeloid cells) and subjected them to stimulation with phorbol myristate acetate (PMA) to provoke ROS production. In response to PMA stimulation, neurofibromin-deficient macrophages generated greater quantities of ROS when compared to 
WT macrophages (Figure 1). In fact, a gene-dosage response was observed in neurofibromindeficient macrophages (Figure 1A and B). The addition of superoxide dismutase (SOD) effectively quenched ROS production, indicating that Nf1 mutant macrophagesproduce excessive superoxide primarily (Figure 1B).

To examine whether Ras activation in neurofibromin-deficient macrophages directly regulates ROS production, we elicited ROS production in WT and $\mathrm{Nf}^{+/-}$macrophages with PMA in the presence of PD0325901, an inhibitor of Ras-Mek-Erk, and wortmannin, an inhibitor of Ras-PI-3K. In response to PMA, $\mathrm{Nf1}^{+/}$macrophages produced significantly more ROS when compared with WT macrophages and this response was completely inhibited in the presence of either Erk or Akt inhibitors (Figure 1C). WT macrophages also produced little ROS when coincubated with PD0325901 or wortmannin, which suggests that PMA likely induces ROS production via Ras activation.

\section{$\mathrm{Nf1}^{+/}$SMC are sensitive to oxidative stress.}

Reactive oxygen species modify the response of intracellular signaling pathways, including $\mathrm{p} 21^{\text {Ras }}$, and may exaggerate the response of extracellular growth signals to induce cell proliferation and survival. More specifically, superoxide and its primary byproduct hydrogen peroxide $\left(\mathrm{H}_{2} \mathrm{O}_{2}\right)$ are important mitogens for $\operatorname{SMC}(33-36)$. Based on the observation that neurofibromin-deficient macrophages produce excessive ROS, we isolated SMC from the aortas of WT and $\mathrm{Nf1}^{+/}$mice to interrogate the potential paracrine effects of local ROS production by infiltrating $\mathrm{Nf1}^{+-}$macrophages on arterial SMC in vitro. Under growth-restrictive conditions, $\mathrm{Nf1}^{+/-} \mathrm{SMC}$ exhibit increased proliferation when compared with WT SMC $(11,12,26)$. To account for this inherent advantage, we compared quiescent $\mathrm{Nf}^{+/-}$and WT SMC incubated with/without $\mathrm{H}_{2} \mathrm{O}_{2}$ to mimic exposure to vascular oxidative stress. In response to low micromolar concentrations of $\mathrm{H}_{2} \mathrm{O}_{2}, \mathrm{Nf1^{+/ }} \mathrm{SMC}$ exhibited a dose-responsive increase in thymidine incorporation, while higher concentrations of $\mathrm{H}_{2} \mathrm{O}_{2}$ failed to stimulate $\mathrm{Nf1^{+/- }}$ SMC proliferation 
(Figure 2A). Thymidine incorporation was also dose-responsive in WT SMC, though higher $\mathrm{H}_{2} \mathrm{O}_{2}$ concentrations were required to induce the same proliferative response and statistical significance was not achieved. Interestingly, WT and $\mathrm{Nf}^{+/-}$SMC viability dropped significantly in response to stimulation with $100 \mu \mathrm{M} \mathrm{H}_{2} \mathrm{O}_{2}$ as determined by MTT assay (Figure 2B). Both low and high concentrations of $\mathrm{H}_{2} \mathrm{O}_{2}$ preferentially activated Erk in $\mathrm{Nf1}^{+/} \mathrm{SMC}$ when compared to WT SMC, while Ras-PI-3K activity remained largely unchanged (Figure 2C). Consistent with decreased cell viability, incubation of $\mathrm{Nf}^{+/-} \mathrm{SMC}$ with $100 \mu \mathrm{M} \mathrm{H}_{2} \mathrm{O}_{2}$ induced the cleavage of caspase-3, an indicator of apoptosis (Figure 2C). These data suggest that low-level ROS amplifies Erk activity in $\mathrm{Nf}^{+/-} \mathrm{SMC}$ and potentiates $\mathrm{Nf}^{+/-} \mathrm{SMC}$ proliferation, while higher concentrations of $\mathrm{H}_{2} \mathrm{O}_{2}$ may induce $\mathrm{Nf}^{+/-} \mathrm{SMC}$ apoptosis. The latter is an important observation since SMC apoptosis is a critical step in the development of aortic aneurysms, which is a less common manifestation of NF1 vasculopathy(2, 37).Additionally, we examined $\mathrm{Nf}^{+/-}$and WT SMC for native ROS production in response to incubation with $\mathrm{H}_{2} \mathrm{O}_{2}$ to identify particular advantages that neurofibromin-deficiency and/or Ras activation might have on ROS production. Quiescent $\mathrm{Nf1}^{+/-}$and WT SMC exhibited similar basal ROS production and the addition of $\mathrm{H}_{2} \mathrm{O}_{2}$ (10 and $100 \mu \mathrm{M})$ did not confer additional ROS production in $\mathrm{Nf1}^{+/-} \mathrm{SMC}$ when compared with WT SMC (data not shown). Thus, it is unlikely that $\mathrm{Nf1}^{+/}$SMC produce sufficient quantities of ROS to autonomously induce SMC proliferation and arterial stenosis de novo, but may confer an additive effect to local ROS production by infiltrating macrophages.

NOX2 expression is upregulated in $\mathrm{Nf}^{+/-}$carotid arteries.

Previously, we showed that $N f 1^{+/}$mice develop exaggerated neointimas and excessive remodeling when compared with WT mice, which is largely mediated by neurofibromin-deficient monocytes/macrophages $(9,11)$. While loss of neurofibromin expression leads to increase Ras signaling and enhances macrophage survival and function, the inciting mechanism(s) leading to rampant SMC proliferation and neointima formation are poorly understood. To examine the 
potential role of excessive ROS production by $\mathrm{Nf}^{+/-}$macrophages on the vascular wall, we harvested control and ligated arteries from $\mathrm{Nf}^{+/-}$and WT mice 3 days after injury. Prior to tissue harvest, animals were provided dihydroethidium (DHE) via IP injection to detect ROS in the vascular wall. In comparison to control vessels, injured arteries from both genotypes exhibited increase DHE staining indicating an upregulation in ROS production (Figure 3A). However, injured $\mathrm{Nf}^{+/-}$arteries showed only a modest increase in ROS expression compared to injured WT arteries at this early time point. Next, control and injured carotid arteries from $\mathrm{Nf}^{+/-}$and WT mice were pooled and analyzed for NOX2 expression. Interestingly, control $\mathrm{Nf}^{+/-}$arteries have increased expression of NOX2 compared to WT control arteries (Figure 3B). In response to arterial ligation, both WT and $\mathrm{Nf}^{+/-}$carotid arteries have enhanced expression of NOX2 compared to genotype-specific controls, though injured $\mathrm{Nf}^{+/-}$arteries exhibited the highest NOX2 expression of all conditions tested. Although examination of an early time point after arterial injury did not detect significant differences in ROS production in the vessel wall between $\mathrm{Nf}^{+/-}$and WT arteries, NOX2 expression in whole artery lysates suggest that neurofibromin regulates the expression of NOX2 and NOX2 expression is increased during early inward arterial remodeling.

\section{NOX2 activation is required for $\mathrm{Nf1}^{+/-}$neointima formation.}

Excessive ROS production by infiltrating leukocytesin the vascular wall contributes to SMC proliferation and arterial stenosis $(34,38)$ and therapeutic attempts to scavenge excess ROS or interrupt ROS production have proven efficacious in preclinical models of neointima formation(39). Superoxide production in leukocytes is largely mediated via NADPH oxidase 2 (NOX2), which is activated, in part, by the Ras-dependent kinases Erk and Akt(17, 28, 40). Based on our observation that neurofibromin-deficient macrophages produce excessive superoxide and $\mathrm{Nf1}^{+/} \mathrm{SMC}$ proliferation is dose-responsive to ROS species, we intercrossed $\mathrm{Nf} 1^{+/-}$mice with $p 47^{\text {phox }}$ knockout mice to understand the role of NOX2 activation in $\mathrm{Nf} 1^{+/-}$ 
neointima formation. In response to carotid artery ligation, $\mathrm{Nf1}^{+/-}$mice developed an enhanced neointima, which was phenotypically and histologically similar to our previous observations (Figure 3). Genetic deletion of $p 47^{\text {phox }}$, a cytosolic component of NOX2 that is required for NOX2 activation, reduced neointima formation in $\mathrm{Nf}^{+/-}$mice to levels observed in the background strain. Quantitative analysis of arterial cross sections from each cohort demonstrated a $65 \%$ reduction in neointima area and $80 \%$ reduction in intima/media $(\mathrm{I} / \mathrm{M})$ ratio (Figure 3B and C). Thus, p47 $7^{\text {phox }}$ expression is required for $\mathrm{Nf1^{+/- }}$ neointima formation and NOX2 activation may be mechanistically responsible for the enhanced ROS production observed in Nf1 mutant macrophages.

Previously, we utilized $L y s M^{\text {cre }}$ mice to demonstrate that loss of a singleNf1 gene copy in monocytes/macrophages is sufficient to reproduce the enhanced neointima observed in neurofibromin-deficient mice(11). In order to specifically interrogate the role of macrophagespecific ROS production in the pathogenesis of Nf1 arterial stenosis, we intercrossed $N f 1^{f l o x /+} ; L y s M^{\text {cre }}$ mice with $g p 91^{\text {flox/flox }}$ mice to generate $N f 1^{f l o x /+} ; g p 91^{f l o x / f l o x} ;$ $L y s M^{\text {cre }}$ mice with specific deletion of both $\mathrm{gp} 91^{\text {phox }}$ alleles in $\mathrm{Nf1^{+- }}$ monocytes and macrophages. gp $91^{\text {phox }}$ is the glycosylated membrane-bound component of NOX2 and is required for electron transfer to molecular oxygen in the generation of superoxide(41). $\mathrm{Cre}^{+}$and $\mathrm{Cre}^{-}$mice were subjected to carotid artery ligation to induce neointima formation. Lineage-restricted inactivation of a single Nf1 allele in myeloid cells alone was sufficient to induce a robust neointima that is an exact phenocopy of neointimas observed in $\mathrm{Nf}^{+/-}$mice after arterial injury (Figure 4). In contrast, genetic deletion of both $g p 91^{\text {phox }}$ allelesin $N f 1^{f l o x /+} ; L y s M^{\text {cre }}$ mice resulted in a $75 \%$ reduction in neointima formation after arterial injury when compared toNf1 ${ }^{f l o x /+} ; L y s M^{\text {cre }}$ mice (Figure 4B and C). Collectively, these data provide genetic evidence that the presence and activation of NOX2 is necessary for $\mathrm{Nf}^{+/-}$neointima formation and limiting ROS production may be a viable therapeutic target for the prevention and/or treatment of NF1 arterial stenosis. 


\section{Apocynin inhibits neointima formation in $\mathrm{Nf1}^{+/-}$mice.}

The proximity of invading $\mathrm{Nf}^{+/-}$macrophages to vascular wall SMC and their propensity for superoxide production may be pathologically linked to neointima formation in $\mathrm{Nf}^{+/-}$mice. Sequestering ROS production provides an attractive therapeutic option since anti-oxidants are well tolerated and may be particularly effective in NF1 patients with evidence of oxidative stress. The antioxidant apocynin is intriguing since it binds the p47 subunit in the cytosol and interferes with NOX2 activation(42-44). Therefore, we subjected $\mathrm{Nf}^{+/-}$and WT mice to carotid artery ligation to induce arterial stenosis and provided drinking water containing or lacking apocynin (100mg/kg/day) for 28 days until the arteries were harvested and analyzed for neointima formation. In response to carotid artery injury, WT mice developed a modest neointima while $\mathrm{Nf}^{+/-}$mice developed a severe arterial stenosis, which was similar to our previous observations

(Figure 5). In contrast, daily administration of apocynin reduced $\mathrm{Nf}^{+/-}$neointima area by $75 \%$ in comparison with control $\mathrm{Nf}^{+/-}$mice (Figure 5B and C). WT mice experienced a modest, but non-significant reduction in neointima formation, which is likely due to their resistance to neointima formation.

\section{NF1 patients have increased pro-inflammatory monocytes and evidence of chronic oxidative stress.}

Loss of Nf1 may increase the susceptibility of whole organisms and primary cells to oxidative stress, and previous studies have suggested interplay between chronic oxidative stress and inflammation in tissue derived from NF1 patients. However, evidence of oxidative stress has not been demonstrated in persons with NF1(8, 45-47). Therefore, we isolated peripheral blood MNCs to examine them for evidence of oxidative stress. In comparison with age- and sex-matched controls, total monocyte count was elevated in asymptomatic NF1 patients. Examination of monocyte subpopulation frequency showedthat some healthy persons with NF1 had a substantial increase in the frequency of a monocyte subpopulation 
$\left(\mathrm{CD} 14^{+} \mathrm{CD} 16^{++}\right)$associated with inflammatory conditions and oxidative stress(48-50) (Figure 6A and B). The mean frequency of $\mathrm{CD} 14^{+} \mathrm{CD} 16^{++}$monocytes in the NF1 cohort was 2.5 times higher than the mean frequency of $\mathrm{CD} 14^{+} \mathrm{CD} 16^{++}$monocytes in the control cohort $(40.8 \pm 14$ vs. $15.73 \pm 4.3$ cells/ $\mu \mathrm{L}, P=0.06)$. Within the NF1 cohort, we observed that some NF1 patients exhibited a significant elevation in the frequency of circulating CD14 ${ }^{+}$CD $16^{++}$monocytes, which may cause a positive skew in the sample distribution. To determine if the sample distribution in these two cohorts could occur by random chance, we performed an F-test of variance. This secondary analysis revealed a significant difference in $C D 14^{+} \mathrm{CD} 16^{++}$monocyte frequency variance between NF1 and control patients $(P<0.001)$. Monocyte subpopulation frequencies must be interpreted in relationship to controls since normal values do not presently exist. While nearly $60 \%$ of healthy controls had a $\mathrm{CD} 14^{+} \mathrm{CD} 16^{++}$monocyte frequency of less than 10,000 cells $/ \mu \mathrm{L}$ in their peripheral blood, less than $45 \%$ of healthy persons with NF1 met the same cutoff value. In fact, the highest $\mathrm{CD} 14^{+} \mathrm{CD} 16^{++}$monocyte frequency observed in persons with NF1 were 2-3 fold higher than the highest observed frequencies in control patients (Figure 6B). In comparison, the frequency of patrolling or "classical" monocytes did not differ between control and NF1 patients (329 \pm 131 vs. $416 \pm 188$ cells $/ \mu \mathrm{L}, P=0.2)$. Since CD14 ${ }^{++} \mathrm{CD} 16^{-}$classical monocytes arise from the bone marrow and give rise to $C D 14^{++} \mathrm{CD} 16^{+}$intermediate and CD $14^{+} \mathrm{CD} 16^{++}$non-classical monocytes, this data suggests that the increased frequency of $\mathrm{CD} 14^{+} \mathrm{CD} 16^{++}$monocytes is the result of signaling inputs outside the bone marrow compartment and do not arise from alterations in developmental maturation(50).

Next, we examined peripheral blood MNCs for evidence of oxidative stress using a modified comet assay to analyze for oxidative DNA damage. Monocytes isolated from NF1 patients displayed a 2-fold increase in oxidative DNA damage when compared with control patients (Figure 6C). Thus, NF1 patients have evidence of chronic oxidative stress and inflammation, which may predispose them to premature and/or severe forms of cardiovascular disease. 


\section{Discussion}

Despite a high propensity for severe forms of cardiovascular disease, tailored therapies for NF1 patients withvasculopathy are nonexistent. The lack of a concise therapeutic approach to NF1 vasculopathy is largely due to a poor understanding of disease pathogenesis and latency in disease presentation. To date, most therapeutic studies have targeted downstream Ras kinases as their activity is deregulated and amplified in persons with NF1. While Ras pathway inhibitors are mechanistically plausible for the treatment of cardiovascular manifestations in NF1 patients, long-term treatment of cardiovascular diseases with Mek-Erk or Ras-PI-3K inhibitors is not practical due to the necessity of this highly conserved pathway in normal cell growth and differentiation. Thus, the need for highly efficacious and well-tolerated compounds for persons with NF1 vasculopathy must leverage the unique biochemistry found in neurofibromin-deficient tissue while maintaining a favorable side-effect profile.

Emerging evidence suggests that oxido-reductive balance is disturbed in active Ras mutants and neurofibromin-deficient tissues and humans. The interaction between ROS and Ras is multifaceted, but reactive oxygen and nitrogen species have been identified as upstream modulators and downstream targets of several Ras kinases(13). Active Ras mutations or upregulation of Ras signaling leads to increased expression of NADPH oxidases to enhance ROS production in multiple cell types $(17,51-53)$. Ras activation through growth factor binding of various receptor tyrosine kinases may cooperate with small molecule modulators, such as ROS, to enhance phosphorylation of the downstream kinases Erk and Akt(54). In turn, inhibition of ROS production appears to decrease Erk and Akt activity so that signaling feedback between ROS and Ras is critical for cell homeostasis(55-57). The physiologic interaction of ROS and $\mathrm{p} 21^{\text {Ras }}$ may turn pathologic in the setting of neurofibromin-deficiency as evidenced by recent studies. Oligodendrocytes containing either inactivating Nf1 or active HRAS mutations produce excessive ROS leading to disruption of local endothelial tight junctions and increased vascular 
permeability, which is restored with the administration of the antioxidant $\mathrm{N}$-acetyl cysteine(23). Neurofibromin may also express a more direct relationship with mitochondrial ROS production via protein kinase A (PKA). Mutations in the DrosophilaNf1 homolog increased mitochondrial ROS production, shortened lifespan, and sensitized flies to oxidative stress(22). Overexpression of PKA restored a normal response to oxidative stress in Nf1 mutant Drosophila(58). Conversely, overexpression of neurofibromin in Drosophilaprovided resistance to oxidant injury and prolonged mean lifespan. Here, we show that superoxide production by differentiated macrophages is directly regulated by neurofibromin via a gene-dosage dependent mechanism.

In support of neurofibromin's role in ROS production, we provide the first evidence of chronic oxidative stress in NF1 patients, as demonstrated by increased comet tail moment, an indicator of oxidative DNA damage(59). Recent studies suggest that neurofibromin also regulates cell cycle and DNA repair pathways; therefore, loss of neurofibromin may prevent normal DNA repair to occur and may be an alternative explanation for the enhanced oxidative DNA damage(60). However, measurement of direct DNA damage did not differ between NF1 and control patients (data not shown). Regardless, the implications of these findings may be broad-based since excessive ROS production and oxidative DNA damage may participate in several manifestations of NF1, including cancer, impaired learning and cognition, and musculoskeletal diseases. Further, modulating ROS production is an attractive therapeutic alternative for NF1 patients and may have additive effects since neurofibromin restrains ROS production directly and indirectly.

Monocytes and macrophages appear to play a critical role in the pathogenesis of NF1 vasculopathy. Lineage-restricted inactivation of $N f 1$ in myeloid cells leads to a pro-inflammatory monocyte profile in mice and is sufficient to recapitulate the arterial stenosis phenotype observed in persons with NF1(11). Nf1 mutant macrophages are readily recruited to sites of vascular injury and the excessive ROS production by $\mathrm{Nf1}^{+/-}$macrophages appears to promote a proliferative SMC response in vitro and in vivo. Interestingly, PMA elicited more ROS in Nf1 
mutant macrophages as compared to WT macrophages, which was effectively blocked by coincubation with inhibitors of Ras. PMA is a potent stimulus for NADPH via Ras-Erk dependent and independent mechanisms and may explain the exaggerated response of $\mathrm{Nf}^{+/-}$and $\mathrm{Nf}^{-/-}$ macrophages to PMA(61-64). Increased production of ROS may propagate a pro-survival macrophage phenotype and increase the generation and secretion of pro-inflammatory cytokines, although this has yet to be demonstrated(65). Neurofibromin's role in regulating monocyte/macrophage-mediated ROS is further emphasized by the observation that apocynin significantly inhibited neointima formation in $\mathrm{Nf}^{+/}$mice while having little effect on WT neointima formation. Although apocynin is generally recognized as a nonspecific antioxidant in vascular wall cells, Heumuller et al. concluded that apocynin dimerizes in myeloperoxidaseexpressing cells, including macrophages, and suppresses superoxide production in leukocytes by inhibiting the binding of the cytosolic $\mathrm{p} 47^{\text {phox }}$ subunit to the transmembrane NOX2 complex(42).Apocynin's dual roles as an antioxidant and specific inhibitor of NOX2 activity likely contribute to the reduced neointima formation observed in $\mathrm{Nf1}^{+/-}$mice. These observations are supported by our findings that genetic deletion of $p 47^{\text {phox }}$ or myeloid cell specific inactivation of gp $91^{\text {phox }}$ inhibited neointima formation in $N f 1^{+/-}$mice. Further, the activation of $p 47^{\text {phox }}$ is highly regulated by the Ras dependent kinases Erk and Akt, which is required for NOX2 activation and superoxide production in circulating phagocytes(66-68).Directly targeting NOX2 for the prevention and/or treatment of NF1-related arterial stenosis may not be viable as NOX2 is critical for respiratory burst and phagocytosis, though clinical trails of small molecule NOX inhibitors are forthcoming(40).

Antioxidants, on the other hand, have yielded promising results in multiple preclinical models of arterial stenosis, but human clinical trials have demonstrated only a modest effect(6971). Inhibition of ROS production or sequestering its activity via antioxidant therapy may provide a greater beneficial effect in patients with active Ras mutations, including NF1, than that observed in the general population since small perturbations in kinase activity precipitate a 
dramatic increase in downstream signaling. For example, anti-oxidant therapy significantly reduced vascular wall ROS in $\mathrm{Nf}^{+/-}$aortas exposed to angiotensin II (Angll) while having minimal effect on ROS in WT aortas(72). The preferential effect of antioxidant therapy in $\mathrm{Nf1}^{+/-}$ mice may be explained by the high numbers of macrophages observed in $\mathrm{Nf}^{+/-}$aortas exposed to Angll resulting in an abundance of oxidant species. Interestingly, low dose simvastatin,an HMG-CoA reductase inhibitor with anti-oxidant properties, effectively blocked ROS production in $\mathrm{Nf}^{+/-}$aortas exposed to Angll with only a modest treatment effect observed in WT aortas exposed to Angll. While the pleiotropic effects of statins are widely studied, their function as an inhibitor of prenylation has made them an attractive therapy for NF1 patients since prenylation is required for Ras activation(73). The ability of statins to modulate Ras activity and scavenge oxidative species may cooperate to limit the production and local concentration of ROS within the vascular wall. Statins have proven beneficial for a variety of NF1 manifestations including cognitive deficits, behavioral impairment, bone dysplasia and healing in preclinical models, but randomized trials in NF1 patients have yielded mixed results(11, 74-77). To date, no clinical trials for NF1 vasculopathy have been performed.

In summary, our study identifies a novel role for neurofibromin signaling in the generation of reactive oxygen species and provides genetic and pharmacologic evidence that excessive ROS is linked to NF1 vasculopathy. Further, we provide the first human data to suggest that NF1 patients experience chronic oxidative stress. As neurofibromin-deficient myeloid cells are critical cellular mediators of multiple manifestations of NF1, our findings provide a framework for interrogating ROS in NF1 biology and the rational design of clinical trials using antioxidants for NF1 vasculopathy.

\section{Acknowledgements}

This work is supported by the Department of Defense (NF140031, B.K.S. and NF073122, D.A.I.), the American Heart Association (15SDG25500005, B.K.S.), the Department 
of Pediatrics at Augusta University (B.K.S.), and the National Institutes of Health (P50 NS052606, D.A.I.). Additionally, the authors thank Emily Sims and Matthew Repass of the Angio BioCore at the Melvin and Bren Simon Cancer Center for processing the human blood samples for this study, and the assistance of the Flow Cytometry Resource Facility. 


\section{References}

1. Ratner N, and Miller SJ. A RASopathy gene commonly mutated in cancer: the neurofibromatosis type 1 tumour suppressor. Nat Rev Cancer. 2015;15(5):290301.

2. Friedman JM, Arbiser J, Epstein JA, Gutmann DH, Huot SJ, Lin AE, McManus B, and Korf BR. Cardiovascular disease in neurofibromatosis 1: report of the NF1 Cardiovascular Task Force. Genet Med. 2002;4(3):105-11.

3. Lin AE, Birch PH, Korf BR, Tenconi R, Niimura M, Poyhonen M, Armfield Uhas K, Sigorini M, Virdis R, Romano C, et al. Cardiovascular malformations and other cardiovascular abnormalities in neurofibromatosis 1. Am J Med Genet. 2000;95(2):108-17.

4. Oderich GS, Sullivan TM, Bower TC, Gloviczki P, Miller DV, Babovic-Vuksanovic D, Macedo TA, and Stanson A. Vascular abnormalities in patients with neurofibromatosis syndrome type I: clinical spectrum, management, and results. Journal of vascular surgery : official publication, the Society for Vascular Surgery [and] International Society for Cardiovascular Surgery, North American Chapter. 2007;46(3):475-84.

5. Rea D, Brandsema JF, Armstrong D, Parkin PC, deVeber G, MacGregor D, Logan WJ, and Askalan R. Cerebral arteriopathy in children with neurofibromatosis type 1. Pediatrics. 2009;124(3):e476-83.

6. Rosser TL, Vezina G, and Packer RJ. Cerebrovascular abnormalities in a population of children with neurofibromatosis type 1. Neurology. 2005;64(3):5535.

7. Rasmussen SA, and Friedman JM. NF1 gene and neurofibromatosis 1. American journal of epidemiology. 2000;151(1):33-40.

8. Lasater EA, Li F, Bessler WK, Estes ML, Vemula S, Hingtgen CM, Dinauer MC, Kapur R, Conway SJ, and Ingram DA, Jr. Genetic and cellular evidence of vascular inflammation in neurofibromin-deficient mice and humans. J Clin Invest. 2010;120(3):859-70.

9. Lasater EA, Bessler WK, Mead LE, Horn WE, Clapp DW, Conway SJ, Ingram $\mathrm{DA}$, and Li F. Nf1+/- mice have increased neointima formation via hyperactivation of a Gleevec sensitive molecular pathway. Hum Mol Genet. 2008;17(15):233644.

10. Stansfield BK, Bessler WK, Mali R, Mund JA, Downing BD, Kapur R, and Ingram $\mathrm{DA}$, Jr. Ras-mek-erk signaling regulates $\mathrm{nf1}$ heterozygous neointima formation. Am J Pathol. 2014;184(1):79-85.

11. Stansfield BK, Bessler WK, Mali R, Mund JA, Downing B, Li F, Sarchet KN, DiStasi MR, Conway SJ, Kapur R, et al. Heterozygous inactivation of the Nf1 gene in myeloid cells enhances neointima formation via a rosuvastatin-sensitive cellular pathway. Hum Mol Genet. 2013;22(5):977-88.

12. Bessler WK, Kim G, Hudson F, Mund JA, Mali R, Menon K, Kapur R, Clapp DW, Ingram DA, Jr., and Stansfield BK. Nf1+/- Monocytes/Macrophages Induce Neointima Formation via CCR2 Activation. Hum Mol Genet. 2016.

13. Brown DI, and Griendling KK. Regulation of signal transduction by reactive oxygen species in the cardiovascular system. Circ Res. 2015;116(3):531-49. 
14. Ferro E, Goitre L, Baldini E, Retta SF, and Trabalzini L. Ras GTPases are both regulators and effectors of redox agents. Methods Mol Biol. 2014;1120(55-74.

15. Mitchell L, Hobbs GA, Aghajanian A, and Campbell SL. Redox regulation of Ras and Rho GTPases: mechanism and function. Antioxidants \& redox signaling. 2013;18(3):250-8.

16. Hole PS, Pearn L, Tonks AJ, James PE, Burnett AK, Darley RL, and Tonks A. Ras-induced reactive oxygen species promote growth factor-independent proliferation in human CD34+ hematopoietic progenitor cells. Blood. 2010;115(6):1238-46.

17. Adachi $\mathrm{Y}$, Shibai $\mathrm{Y}$, Mitsushita J, Shang $\mathrm{WH}$, Hirose $\mathrm{K}$, and Kamata $\mathrm{T}$. Oncogenic Ras upregulates NADPH oxidase 1 gene expression through MEKERK-dependent phosphorylation of GATA-6. Oncogene. 2008;27(36):4921-32.

18. Li XJ, Goodwin CB, Nabinger SC, Richine BM, Yang Z, Hanenberg H, Ohnishi H, Matozaki T, Feng GS, and Chan RJ. Protein-tyrosine phosphatase Shp2 positively regulates macrophage oxidative burst. The Journal of biological chemistry. 2015;290(7):3894-909.

19. Bhatt NY, Kelley TW, Khramtsov VV, Wang Y, Lam GK, Clanton TL, and Marsh $\mathrm{CB}$. Macrophage-colony-stimulating factor-induced activation of extracellularregulated kinase involves phosphatidylinositol 3-kinase and reactive oxygen species in human monocytes. $J$ Immunol. 2002;169(11):6427-34.

20. Hannan F, Ho I, Tong JJ, Zhu Y, Nurnberg P, and Zhong Y. Effect of neurofibromatosis type I mutations on a novel pathway for adenylyl cyclase activation requiring neurofibromin and Ras. Hum Mol Genet. 2006;15(7):1087-98.

21. Tong J, Hannan F, Zhu Y, Bernards A, and Zhong Y. Neurofibromin regulates G protein-stimulated adenylyl cyclase activity. Nature neuroscience. 2002;5(2):956.

22. Tong JJ, Schriner SE, McCleary D, Day BJ, and Wallace DC. Life extension through neurofibromin mitochondrial regulation and antioxidant therapy for neurofibromatosis-1 in Drosophila melanogaster. Nat Genet. 2007;39(4):476-85.

23. Mayes DA, Rizvi TA, Titus-Mitchell H, Oberst R, Ciraolo GM, Vorhees CV, Robinson AP, Miller SD, Cancelas JA, Stemmer-Rachamimov AO, et al. Nf1 loss and Ras hyperactivation in oligodendrocytes induce NOS-driven defects in myelin and vasculature. Cell reports. 2013;4(6):1197-212.

24. Ingram DA, Hiatt K, King AJ, Fisher L, Shivakumar R, Derstine C, Wenning MJ, Diaz B, Travers JB, Hood A, et al. Hyperactivation of p21(ras) and the hematopoietic-specific Rho GTPase, Rac2, cooperate to alter the proliferation of neurofibromin-deficient mast cells in vivo and in vitro. J Exp Med. 2001;194(1):57-69.

25. Yan J, Chen S, Zhang Y, Li X, Li Y, Wu X, Yuan J, Robling AG, Kapur R, Chan RJ, et al. Rac1 mediates the osteoclast gains-in-function induced by haploinsufficiency of Nf1. Hum Mol Genet. 2008;17(7):936-48.

26. Li F, Munchhof AM, White HA, Mead LE, Krier TR, Fenoglio A, Chen S, Wu X, Cai $S$, Yang FC, et al. Neurofibromin is a novel regulator of RAS-induced signals in primary vascular smooth muscle cells. Hum Mol Genet. 2006;15(11):1921-30. 
27. Panday A, Sahoo MK, Osorio D, and Batra S. NADPH oxidases: an overview from structure to innate immunity-associated pathologies. Cellular \& molecular immunology. 2015;12(1):5-23.

28. Berton G, Castaldi MA, Cassatella MA, and Nauseef WM. Editorial: Celebrating the 50th anniversary of the seminal discovery that the phagocyte respiratory burst enzyme is an NADPH oxidase. J Leukoc Biol. 2015;97(1):1-2.

29. Griendling KK, Sorescu D, and Ushio-Fukai M. NAD $(P) H$ oxidase: role in cardiovascular biology and disease. Circ Res. 2000;86(5):494-501.

30. Gutmann DH, Aylsworth A, Carey JC, Korf B, Marks J, Pyeritz RE, Rubenstein A, and Viskochil $D$. The diagnostic evaluation and multidisciplinary management of neurofibromatosis 1 and neurofibromatosis 2. JAMA : the journal of the American Medical Association. 1997;278(1):51-7.

31. Yoder MC, Mead LE, Prater D, Krier TR, Mroueh KN, Li F, Krasich R, Temm CJ, Prchal JT, and Ingram DA. Redefining endothelial progenitor cells via clonal analysis and hematopoietic stem/progenitor cell principals. Blood. 2007;109(5):1801-9.

32. Azqueta A, Gutzkow KB, Brunborg G, and Collins AR. Towards a more reliable comet assay: optimising agarose concentration, unwinding time and electrophoresis conditions. Mutat Res. 2011;724(1-2):41-5.

33. Li PF, Dietz R, and von Harsdorf R. Differential effect of hydrogen peroxide and superoxide anion on apoptosis and proliferation of vascular smooth muscle cells. Circulation. 1997;96(10):3602-9.

34. Ashino T, Yamamoto M, Yoshida T, and Numazawa S. Redox-sensitive transcription factor Nrf2 regulates vascular smooth muscle cell migration and neointimal hyperplasia. Arterioscler Thromb Vasc Biol. 2013;33(4):760-8.

35. Clempus RE, and Griendling KK. Reactive oxygen species signaling in vascular smooth muscle cells. Cardiovasc Res. 2006;71(2):216-25.

36. Lyle AN, and Griendling KK. Modulation of vascular smooth muscle signaling by reactive oxygen species. Physiology. 2006;21(269-80.

37. Hamilton SJ, and Friedman JM. Insights into the pathogenesis of neurofibromatosis 1 vasculopathy. Clin Genet. 2000;58(5):341-4.

38. Chen $\mathrm{Y}$, Jiang $\mathrm{J}$, Miao $\mathrm{H}$, Chen $\mathrm{X}$, Sun $\mathrm{X}$, and $\mathrm{Li} \mathrm{Y}$. Hydrogen-rich saline attenuates vascular smooth muscle cell proliferation and neointimal hyperplasia by inhibiting reactive oxygen species production and inactivating the RasERK1/2-MEK1/2 and Akt pathways. International journal of molecular medicine. 2013;31(3):597-606.

39. Liu SL, Li YH, Shi GY, Tang SH, Jiang SJ, Huang CW, Liu PY, Hong JS, and Wu $\mathrm{HL}$. Dextromethorphan reduces oxidative stress and inhibits atherosclerosis and neointima formation in mice. Cardiovasc Res. 2009;82(1):161-9.

40. Altenhofer S, Radermacher KA, Kleikers PW, Wingler K, and Schmidt $\mathrm{HH}$. Evolution of NADPH Oxidase Inhibitors: Selectivity and Mechanisms for Target Engagement. Antioxidants \& redox signaling. 2015;23(5):406-27.

41. Yu L, Quinn MT, Cross AR, and Dinauer MC. Gp91(phox) is the heme binding subunit of the superoxide-generating NADPH oxidase. Proc Natl Acad Sci U S A. 1998;95(14):7993-8. 
42. Heumuller S, Wind S, Barbosa-Sicard E, Schmidt HH, Busse R, Schroder K, and Brandes RP. Apocynin is not an inhibitor of vascular NADPH oxidases but an antioxidant. Hypertension. 2008;51(2):211-7.

43. Brandes RP, Weissmann N, and Schroder K. Nox family NADPH oxidases: Molecular mechanisms of activation. Free radical biology \& medicine. 2014;76(208-26.

44. Brandes RP, Weissmann N, and Schroder K. Redox-mediated signal transduction by cardiovascular Nox NADPH oxidases. Journal of molecular and cellular cardiology. 2014;73(70-9.

45. Park SJ, Sawitzki B, Kluwe L, Mautner VF, Holtkamp N, and Kurtz A. Serum biomarkers for neurofibromatosis type 1 and early detection of malignant peripheral nerve-sheath tumors. BMC medicine. 2013;11(109.

46. Mashour GA, Driever PH, Hartmann M, Drissel SN, Zhang T, Scharf B, Felderhoff-Muser U, Sakuma S, Friedrich RE, Martuza RL, et al. Circulating growth factor levels are associated with tumorigenesis in neurofibromatosis type 1. Clinical cancer research : an official journal of the American Association for Cancer Research. 2004;10(17):5677-83.

47. Sullivan K, El-Hoss J, Quinlan KG, Deo N, Garton F, Seto JT, Gdalevitch M, Turner N, Cooney GJ, Kolanczyk M, et al. NF1 is a critical regulator of muscle development and metabolism. Hum Mol Genet. 2014;23(5):1250-9.

48. O'Brien EC, Abdulahad WH, Rutgers A, Huitema MG, O'Reilly VP, Coughlan AM, Harrington M, Heeringa $P$, Little MA, and Hickey FB. Intermediate monocytes in ANCA vasculitis: increased surface expression of ANCA autoantigens and IL1 beta secretion in response to anti-MPO antibodies. Sci Rep. 2015;5(11888.

49. Ziegler-Heitbrock L. Blood Monocytes and Their Subsets: Established Features and Open Questions. Front Immunol. 2015;6(423.

50. Stansfield BK, and Ingram DA. Clinical significance of monocyte heterogeneity. Clinical and translational medicine. 2015;4(5.

51. Komatsu D, Kato M, Nakayama J, Miyagawa S, and Kamata T. NADPH oxidase 1 plays a critical mediating role in oncogenic Ras-induced vascular endothelial growth factor expression. Oncogene. 2008;27(34):4724-32.

52. Alexandrova AY, Kopnin PB, Vasiliev JM, and Kopnin BP. ROS up-regulation mediates Ras-induced changes of cell morphology and motility. Exp Cell Res. 2006;312(11):2066-73.

53. Park MT, Kim MJ, Suh Y, Kim RK, Kim H, Lim EJ, Yoo KC, Lee GH, Kim YH, Hwang SG, et al. Novel signaling axis for ROS generation during K-Ras-induced cellular transformation. Cell death and differentiation. 2014;21(8):1185-97.

54. Svegliati S, Cancello R, Sambo P, Luchetti M, Paroncini P, Orlandini G, Discepoli G, Paterno R, Santillo M, Cuozzo C, et al. Platelet-derived growth factor and reactive oxygen species (ROS) regulate Ras protein levels in primary human fibroblasts via ERK1/2. Amplification of ROS and Ras in systemic sclerosis fibroblasts. The Journal of biological chemistry. 2005;280(43):36474-82.

55. Keshari RS, Verma A, Barthwal MK, and Dikshit M. Reactive oxygen speciesinduced activation of ERK and p38 MAPK mediates PMA-induced NETs release from human neutrophils. Journal of cellular biochemistry. 2013;114(3):532-40. 
56. Luanpitpong S, Chanvorachote $\mathrm{P}$, Nimmannit U, Leonard SS, Stehlik C, Wang L, and Rojanasakul Y. Mitochondrial superoxide mediates doxorubicin-induced keratinocyte apoptosis through oxidative modification of ERK and Bcl-2 ubiquitination. Biochemical pharmacology. 2012;83(12):1643-54.

57. Molognoni $F$, de Melo FH, da Silva CT, and Jasiulionis MG. Ras and Rac1, frequently mutated in melanomas, are activated by superoxide anion, modulate Dnmt1 level and are causally related to melanocyte malignant transformation. PloS one. 2013;8(12):e81937.

58. The I, Hannigan GE, Cowley GS, Reginald S, Zhong Y, Gusella JF, Hariharan IK, and Bernards A. Rescue of a Drosophila NF1 mutant phenotype by protein kinase A. Science. 1997;276(5313):791-4.

59. Collins AR. Measuring oxidative damage to DNA and its repair with the comet assay. Biochim Biophys Acta. 2014;1840(2):794-800.

60. Pemov A, Park C, Reilly KM, and Stewart DR. Evidence of perturbations of cell cycle and DNA repair pathways as a consequence of human and murine NF1haploinsufficiency. BMC Genomics. 2010;11(194.

61. Karlsson A, Nixon JB, and McPhail LC. Phorbol myristate acetate induces neutrophil NADPH-oxidase activity by two separate signal transduction pathways: dependent or independent of phosphatidylinositol 3-kinase. J Leukoc Biol. 2000;67(3):396-404.

62. Frost JA, Geppert TD, Cobb MH, and Feramisco JR. A requirement for extracellular signal-regulated kinase (ERK) function in the activation of AP-1 by Ha-Ras, phorbol 12-myristate 13-acetate, and serum. Proc Natl Acad Sci U S A. 1994;91(9):3844-8.

63. Buscher D, Hipskind RA, Krautwald S, Reimann T, and Baccarini M. Rasdependent and -independent pathways target the mitogen-activated protein kinase network in macrophages. Molecular and cellular biology. 1995;15(1):46675.

64. Smith ME, van der Maesen K, Somera FP, and Sobel RA. Effects of phorbol myristate acetate (PMA) on functions of macrophages and microglia in vitro. Neurochem Res. 1998;23(3):427-34.

65. Anwar A, Keating AK, Joung D, Sather S, Kim GK, Sawczyn KK, Brandao L, Henson PM, and Graham DK. Mer tyrosine kinase (MerTK) promotes macrophage survival following exposure to oxidative stress. J Leukoc Biol. 2009;86(1):73-9.

66. Winiarska K, Jarzyna R, Dzik JM, Jagielski AK, Grabowski M, Nowosielska A, Focht D, and Sierakowski B. ERK1/2 pathway is involved in renal gluconeogenesis inhibition under conditions of lowered NADPH oxidase activity. Free radical biology \& medicine. 2015;81(13-21.

67. Vergori L, Lauret E, Gaceb A, Beauvillain C, Andriantsitohaina R, and Martinez MC. PPARalpha regulates endothelial progenitor cell maturation and myeloid lineage differentiation through a NADPH oxidase-dependent mechanism in mice. Stem Cells. 2015;33(4):1292-303.

68. Kučera J, Binó $L$, Štefková $K$, Jaroš $J$, Vašíček $O$, Večeřa $J$, Kubala $L$, and Pacherník J. Apocynin and Diphenyleneiodonium Induce Oxidative Stress and 
Modulate PI3K/Akt and MAPK/Erk Activity in Mouse Embryonic Stem Cells. Oxidative Medicine and Cellular Longevity. 2015;2016(

69. Kritchevsky SB, Shimakawa T, Tell GS, Dennis B, Carpenter M, Eckfeldt JH, Peacher-Ryan $\mathrm{H}$, and Heiss $\mathrm{G}$. Dietary antioxidants and carotid artery wall thickness. The ARIC Study. Atherosclerosis Risk in Communities Study. Circulation. 1995;92(8):2142-50.

70. Aviram M, Rosenblat M, Gaitini D, Nitecki S, Hoffman A, Dornfeld L, Volkova N, Presser D, Attias J, Liker $\mathrm{H}$, et al. Pomegranate juice consumption for 3 years by patients with carotid artery stenosis reduces common carotid intima-media thickness, blood pressure and LDL oxidation. Clin Nutr. 2004;23(3):423-33.

71. Griendling KK, and FitzGerald GA. Oxidative stress and cardiovascular injury: Part II: animal and human studies. Circulation. 2003;108(17):2034-40.

72. Li F, Downing BD, Smiley LC, Mund JA, Distasi MR, Bessler WK, Sarchet KN, Hinds DM, Kamendulis LM, Hingtgen CM, et al. Neurofibromin-deficient myeloid cells are critical mediators of aneurysm formation in vivo. Circulation. 2014;129(11):1213-24.

73. Cox AD, Der CJ, and Philips MR. Targeting RAS Membrane Association: Back to the Future for Anti-RAS Drug Discovery? Clinical cancer research : an official journal of the American Association for Cancer Research. 2015;21(8):1819-27.

74. Krab LC, de Goede-Bolder A, Aarsen FK, Pluijm SM, Bouman MJ, van der Geest $\mathrm{JN}$, Lequin M, Catsman CE, Arts WF, Kushner SA, et al. Effect of simvastatin on cognitive functioning in children with neurofibromatosis type 1: a randomized controlled trial. JAMA : the journal of the American Medical Association. 2008;300(3):287-94.

75. Wang W, Nyman JS, Moss HE, Gutierrez G, Mundy GR, Yang X, and Elefteriou F. Local low-dose lovastatin delivery improves the bone-healing defect caused by Nf1 loss of function in osteoblasts. Journal of bone and mineral research : the official journal of the American Society for Bone and Mineral Research. 2010;25(7):1658-67.

76. Kolanczyk M, Kuhnisch J, Kossler N, Osswald M, Stumpp S, Thurisch B, Kornak $\mathrm{U}$, and Mundlos $\mathrm{S}$. Modelling neurofibromatosis type 1 tibial dysplasia and its treatment with lovastatin. BMC medicine. 2008;6(21.

77. Acosta MT, Kardel PG, Walsh KS, Rosenbaum KN, Gioia GA, and Packer RJ. Lovastatin as treatment for neurocognitive deficits in neurofibromatosis type 1: phase I study. Pediatric neurology. 2011;45(4):241-5. 
Figure 1: Neurofibromin regulates ROS production via $\mathbf{p} 21^{\text {Ras }}$. WT (red), $N f 1^{+/-}$(green), and $N f 1^{--}$(blue) macrophage ROS production in response to phorbol myristate acid (PMA) in the presence or absence of $\mathrm{p} 21^{\text {Ras }}$ inhibitors. Aand $\mathbf{B}$. Data represent relative light units in response to PMA (A)and in response to PMA with the addition of superoxide dismutase $(\mathbf{B})$ at indicated time point. C. Data represent fold change \pm S.E.M. $(n=4)$ for WT (white bars) and $N f 1^{+/-}$(black bars) macrophage maximal superoxide productionin response to PMA (30 $\mathrm{min}$ ) in the presence or absence of PD0325901 (10nM) and wortmannin (50nM). All comparisons are referred are in reference to unstimulated WT macrophages. ${ }^{*} P<0.01$ for WT versus $N f 1^{+-}$macrophages stimulated with PMA. ${ }^{* *} \mathrm{P}<0.001$ for $\mathrm{WT}$ and $\mathrm{Nf1}^{+/-}$macrophages stimulated with PMA versus WT and $\mathrm{Nf1}^{+-}$macrophages stimulated with PMA in the presence of either PD0325901 or wortmannin.

Figure 2: Low dose $\mathrm{H}_{2} \mathrm{O}_{2}$ induces $\mathrm{Nf1}^{+/-} \mathrm{SMC}$ proliferation and Erk activation. WT (white bars) and $\mathrm{Nf}^{+/-}$(black bars)SMC proliferation in response to stimulation with indicated concentration of $\mathrm{H}_{2} \mathrm{O}_{2}(\mu M)$. A. Data represent genotype-specific fold change $\pm S E M, n=4$. ${ }^{*} \mathrm{P}<0.05$ for $\mathrm{Nf1}^{+/-}$SMC versus $\mathrm{Nf1}{ }^{+/-} \mathrm{SMC}$ stimulated with indicated concentration of $\mathrm{H}_{2} \mathrm{O}_{2}$.B. Data represent genotype-specific SMC viability \pm SEM $(n=4)$ in the presence of $\mathrm{H}_{2} \mathrm{O}_{2} .{ }^{*} P<0.01$ for $\mathrm{Nf}^{+/-} \mathrm{SMC}$ versus $\mathrm{Nf1^{+/ }}$ SMC stimulated with indicated concentration of $\mathrm{H}_{2} \mathrm{O}_{2}$. C. Representative western blots of phospho-Erk, phospho-Akt, pro-caspase 3, cleaved caspase 3, and $\beta$-actin in WT and $N f 1^{+/-}$SMC treated with indicated concentration of $\mathrm{H}_{2} \mathrm{O}_{2}(\mathrm{n}=4)$.

Figure 3: Loss of neurofibromin enhances NOX2 expression in carotid arteries. Representative photomicrographs $(\mathbf{A})$ and NOX2 expression $(\mathbf{B})$ in control and injured carotid arteries from WT and $\mathrm{Nf}^{+/-}$mice $(\mathrm{n}=3)$. A. Fluorescence indicating DHE staining in control and injured WT and $\mathrm{Nf}^{+/-}$arterial cross sections. Scale bars: $400 \mu \mathrm{m}$. B. Representative western blot and quantitative densitometry for NOX2 and $\beta$-actin in pooled samples from WTNf1 ${ }^{+/-}$carotid arteries.

Figure 4: Genetic deletion of $p 47^{\text {phox }}$ inhibits $\mathrm{Nf}^{+/-}$neointima formation. Representative photomicrographs $(\mathbf{A})$ and quantification of neointima area (B and $\mathbf{C}$ ) of injured carotid arteries from WT, $\mathrm{Nf}^{+/-}$, and $\mathrm{Nf1}^{+/-} ; \mathrm{p} 47^{\text {phox-/- }}$ mice. A.Black arrows indicate neointima boundaries. Black boxes identify area of injured artery that is magnified below. Scale bars: $100 \mu \mathrm{m}$. B and C. Quantification of neointima area $(\mathrm{B})$ and I/M ratio $(\mathbf{C})$ of injured carotid arteries from WT, Nf1 ${ }^{+/}$, 


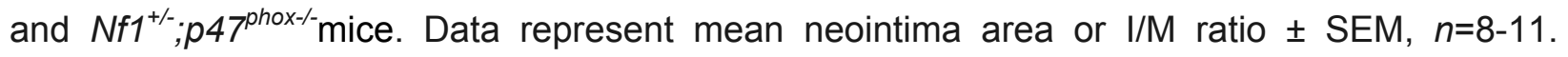

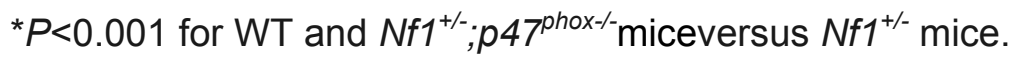

Figure 5: Lineage restricted deletion of $g p 91^{\text {phox }}$ in myeloid cells inhibits $\mathrm{Nf1}^{+/-}$neointima formation. Representative photomicrographs (A) and quantification of neointima area (B and C) of injured carotid arteries from WT, $N f 1^{f l o x /+} ; L_{y s M^{c r e}}$, and $N f 1^{f l o x /+} ; g p 91^{\text {flox/flox }} ; L y s M^{\text {cre }}$ mice. A.Black arrows indicate neointima boundaries. Black boxes identify area of injured artery that is magnified below. Scale bars: $100 \mu \mathrm{m}$. B and C. Quantification of neointima area (B) and I/M

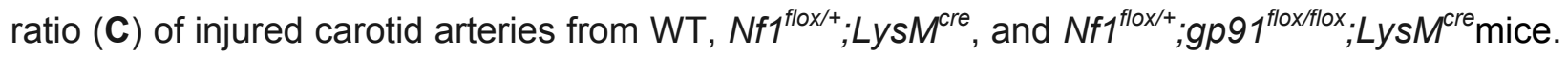
Data represent mean neointima area or I/M ratio \pm SEM, $n=10-12$. ${ }^{*} P<0.001$ for WT, and $N f 1^{f l o x /+} ; g p 91^{\text {flox/flox }}$,LysM ${ }^{\text {cre }}$ mice versus $\mathrm{Nf1}^{\text {flox/+ }} ;$ LysM $^{\text {cre }}$.

Figure 6: Apocynin, a NOX2 inhibitor, reduces $\mathrm{Nf}^{+/-}$neointima formation. Quantification of neointima area $(\mathbf{A})$ and I/M ratio $(\mathbf{B})$ of injured carotid arteries from $\mathrm{WT}$ and $\mathrm{Nf1}{ }^{+/}$mice treated with apocynin $(100 \mathrm{mg} / \mathrm{kg} /$ day) or water.Datarepresent mean neointima area or I/M ratio \pm SEM, $n=8-10$. ${ }^{*} P<0.001$ for WT versus $N f 1^{+/}$mice treated with water. ${ }^{* *} P<0.001$ for $N f 1^{+/-}$mice treated with apocynin versus $\mathrm{Nf}^{+/-}$mice treated with water. No statistical difference was observed between WT mice treated with apocynin and WT mice treated with water.

Figure 7: NF1 patients have evidence of chronic inflammation and oxidative stress.Quantification of total monocyte count (A), CD14 ${ }^{+} \mathrm{CD} 16^{++}$monocyte count (B), and peripheral blood MNC comet tail moment (C) in NF1 patients and age-, sex-matched controls.A. Data represent total monocyte count (cells/ $\mu \mathrm{L})$ for NF1 patients $(n=13)$ and controls $(n=18)$. $P<0.01$ for NF1 patients versus control patients. B. Data represent $\mathrm{CD} 14^{+} \mathrm{CD} 16^{++}$monocytes (cells/ $\mu \mathrm{L})$ for NF1 patients $\left((n=13)\right.$ and controls $(n=17)$. C.Data represent CD14 ${ }^{++} \mathrm{CD}^{-}{ }^{-}$ monocytes (cells/ $\mu \mathrm{L})$ for NF1 patients $((n=13)$ and controls $(n=17)$. D. Data represent mean comet tail moment \pm S.D. for NF1 patients $(n=10)$ versus controls $(n=28)$. $P<0.05$ for NF1 versus control patients. 
Figure 1

A

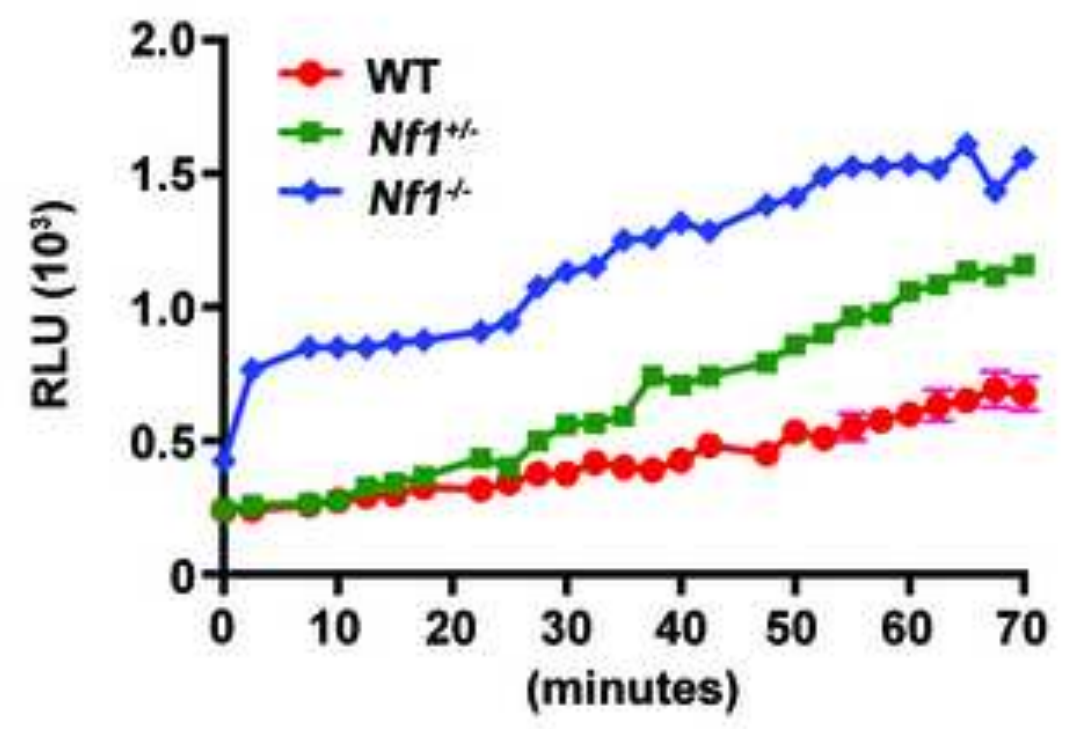

B

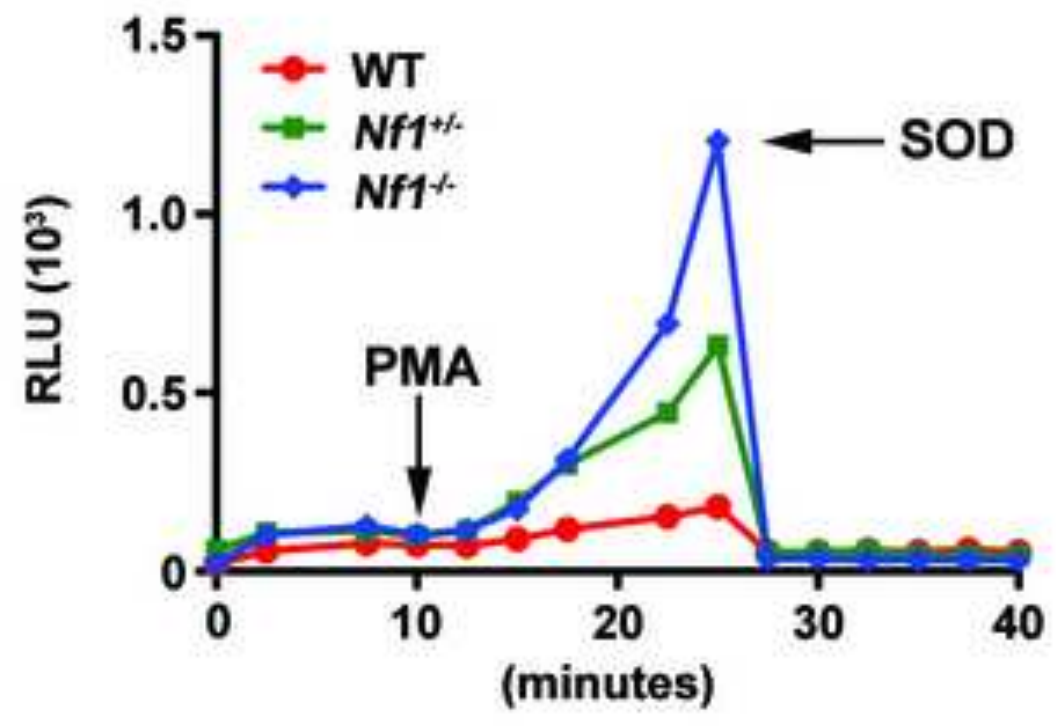

C

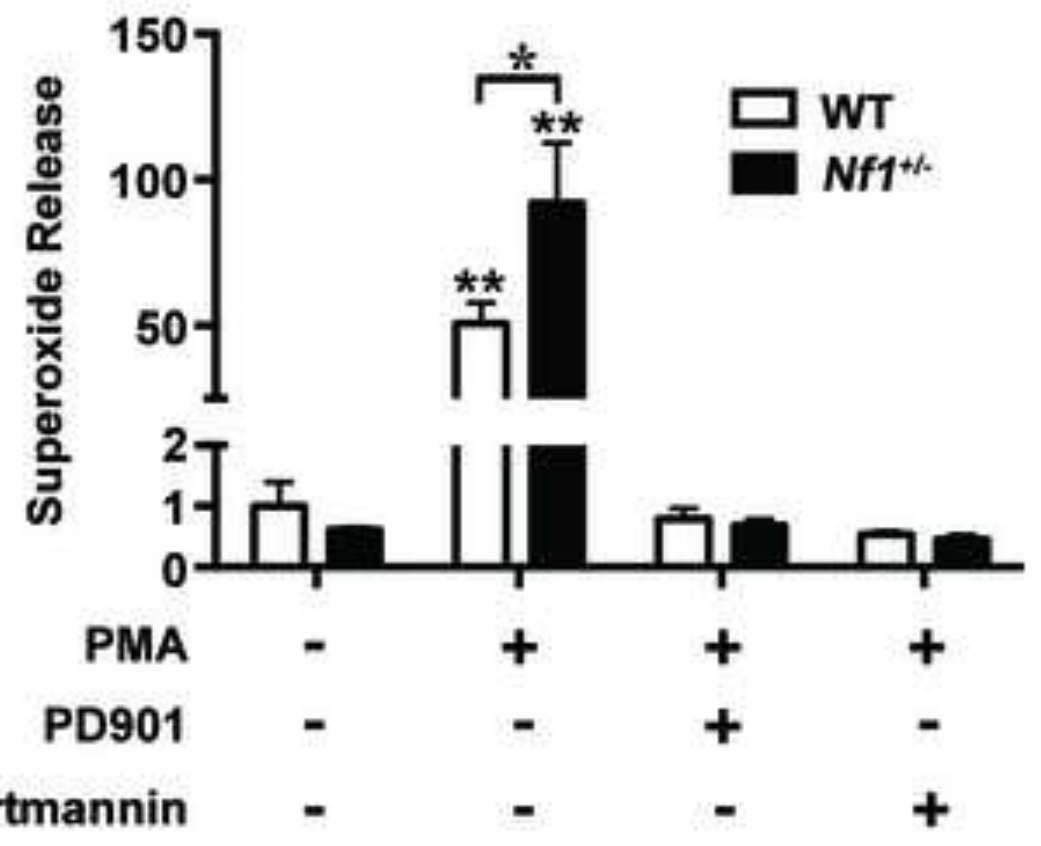


Figure 2
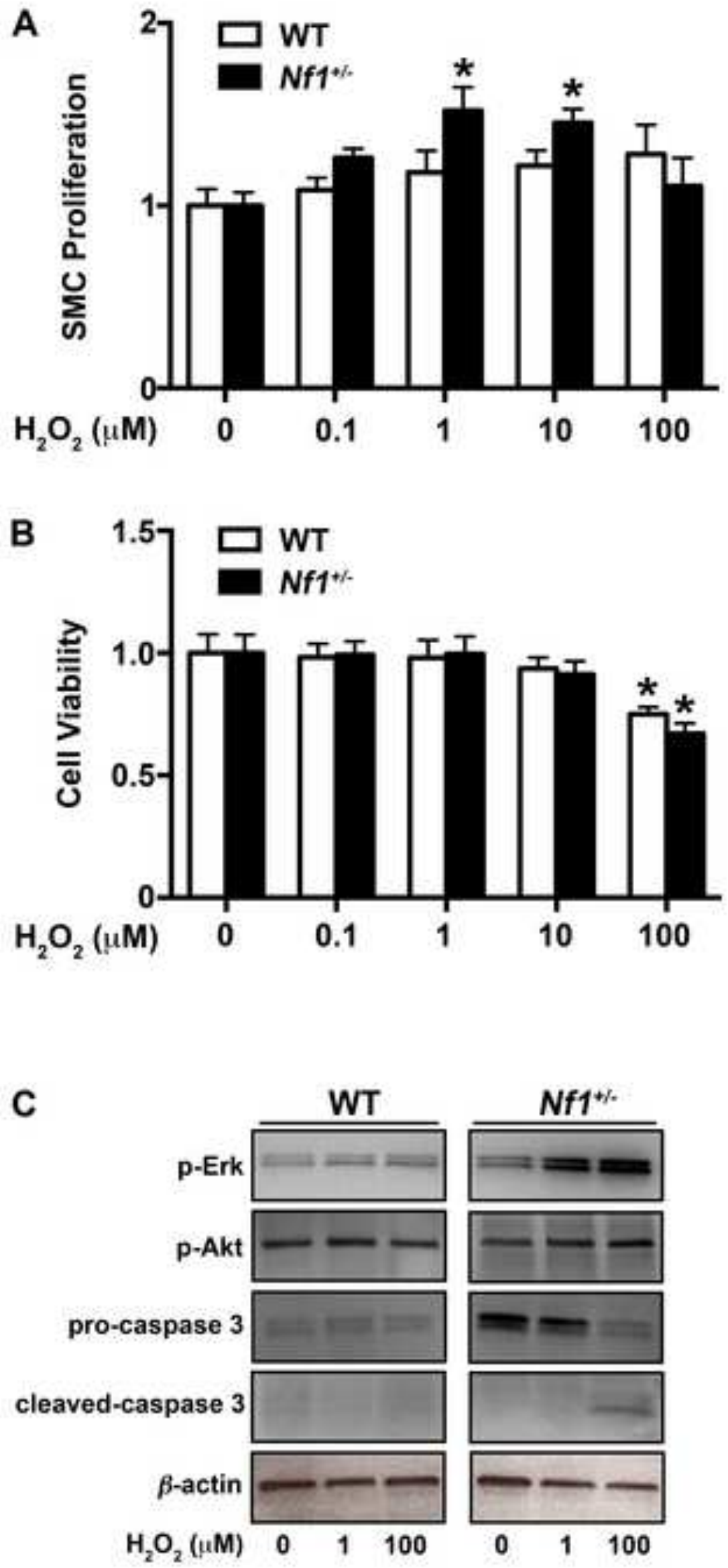
Figure 3

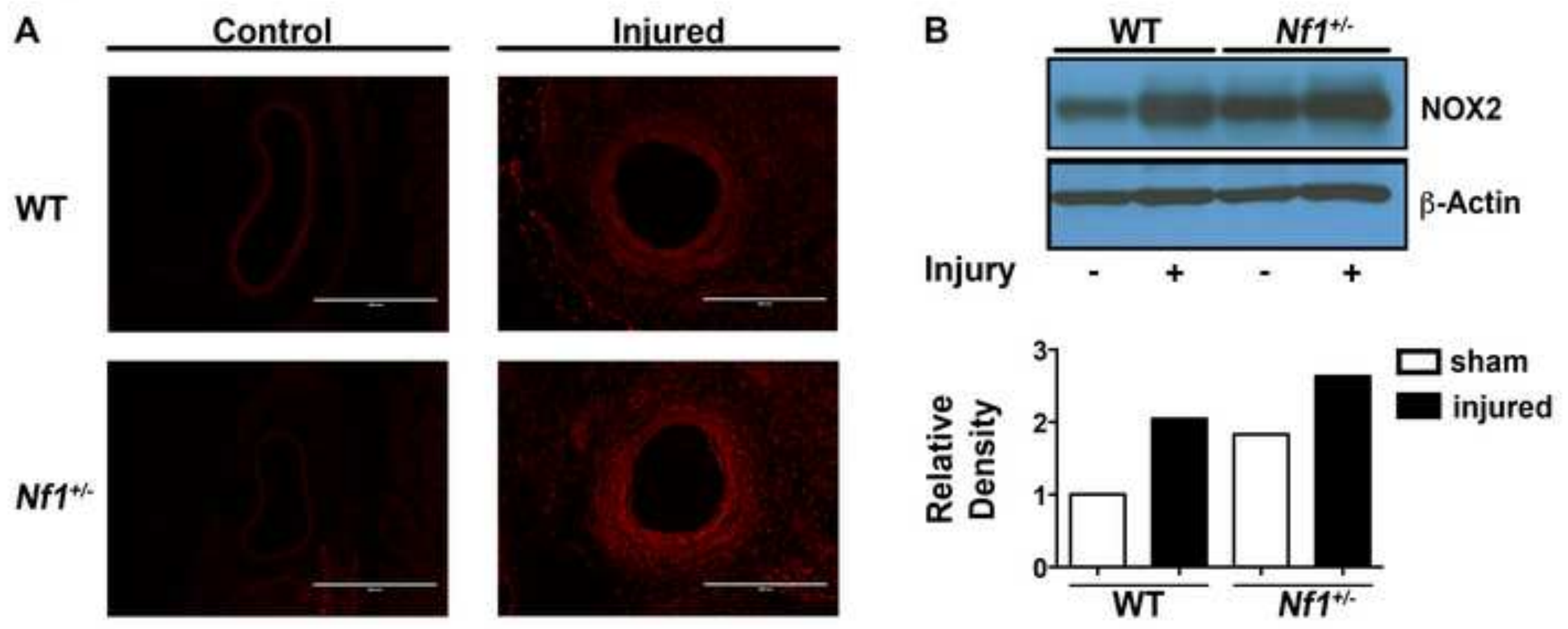


Figure 4

A

WT

$\mathrm{Nf1}^{+/}$

$\mathrm{Nf1}^{+/ \cdots} ; p 47^{\text {phox-l- }}$
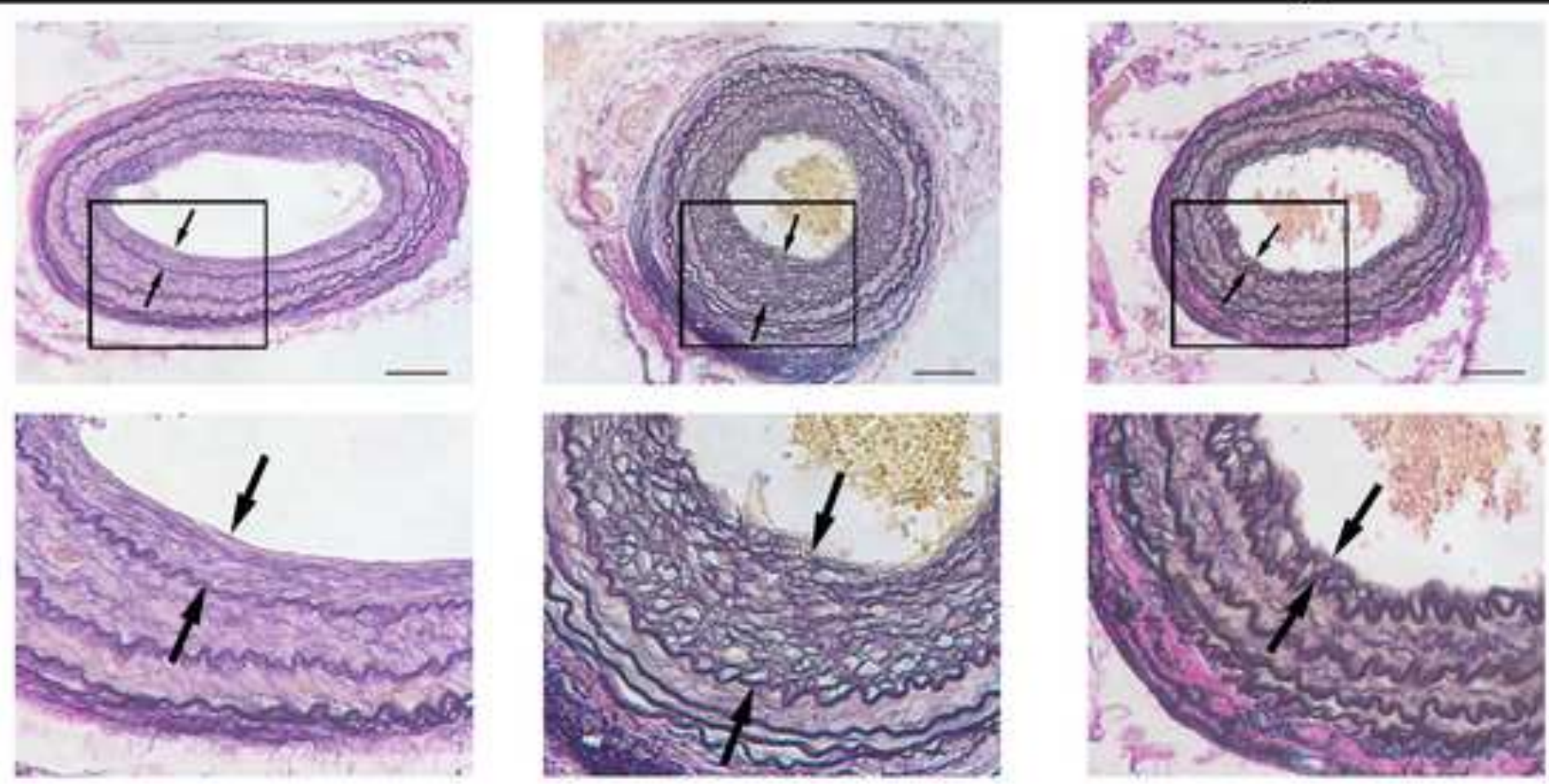

B
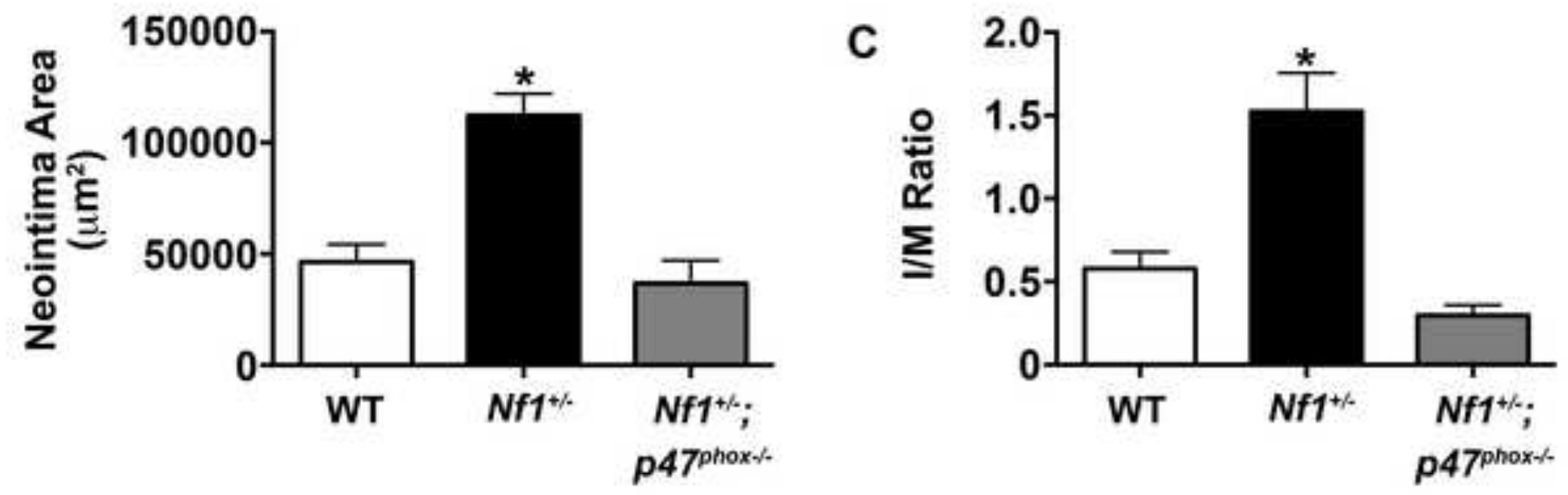
Figure 5

A

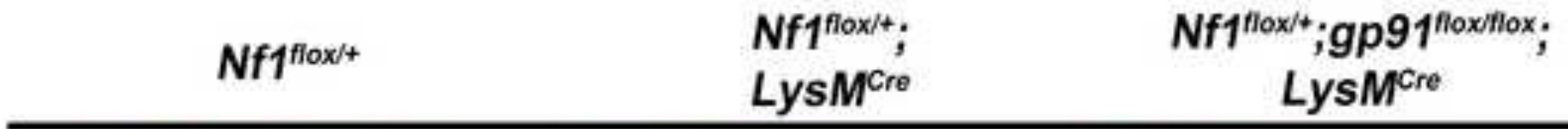
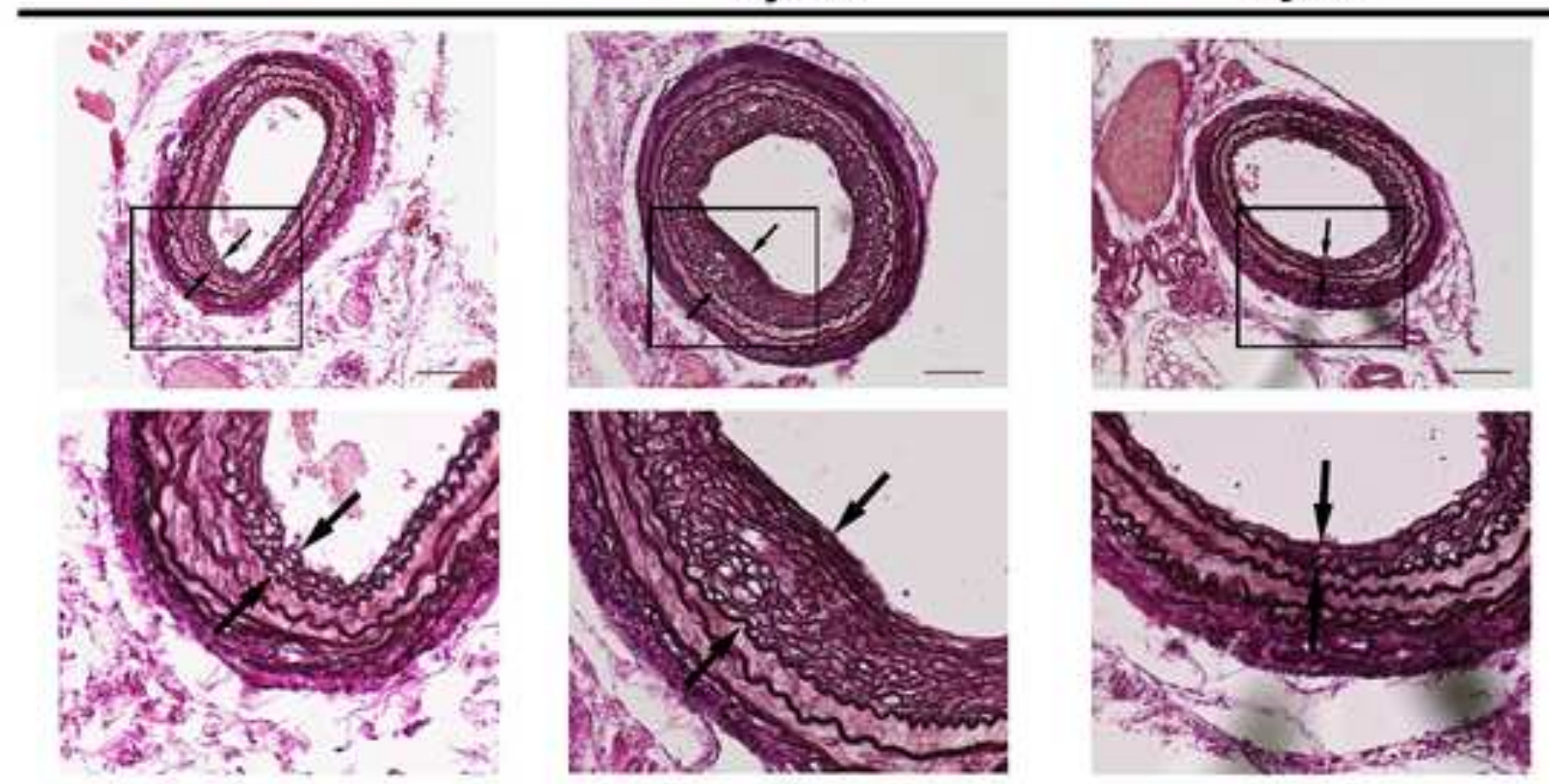

B
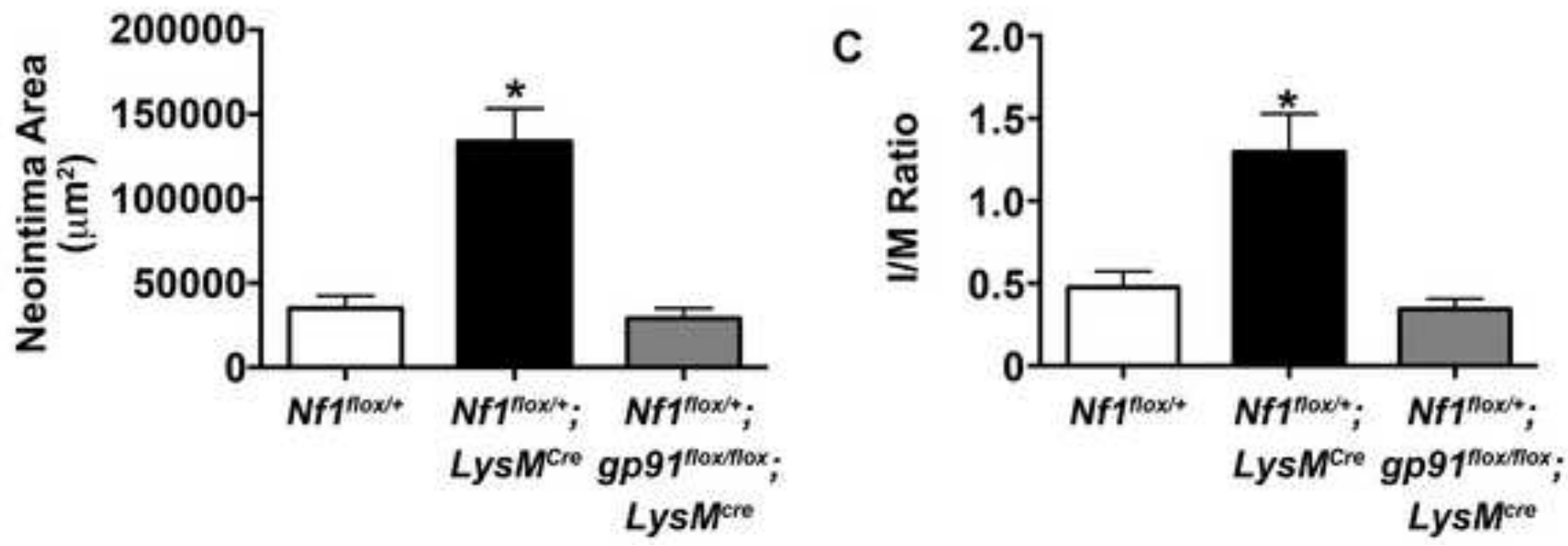
Figure 6
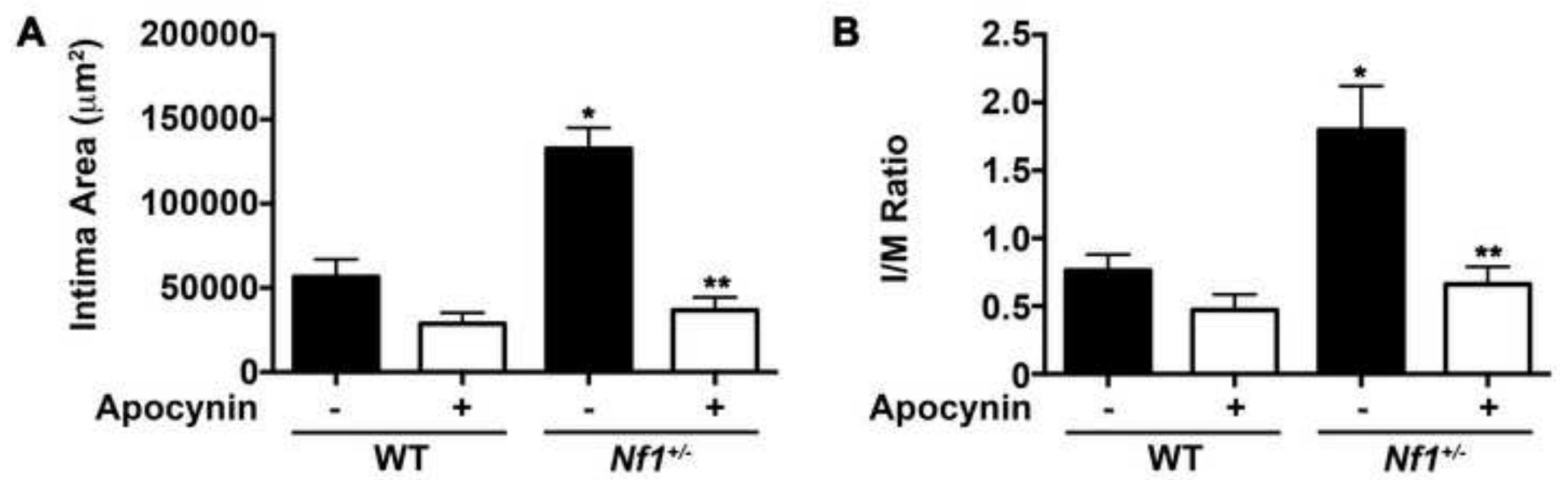
Figure 7
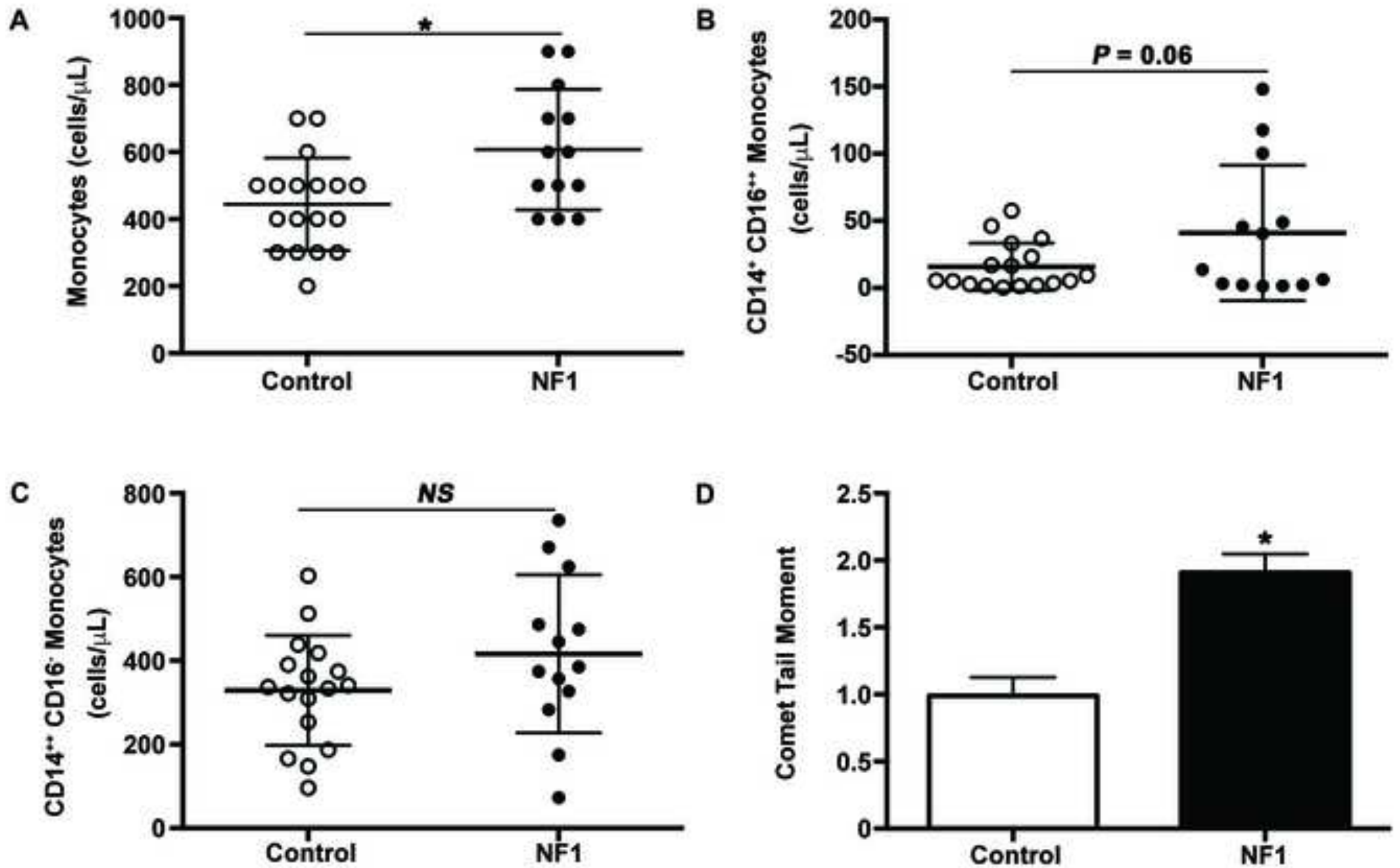

D

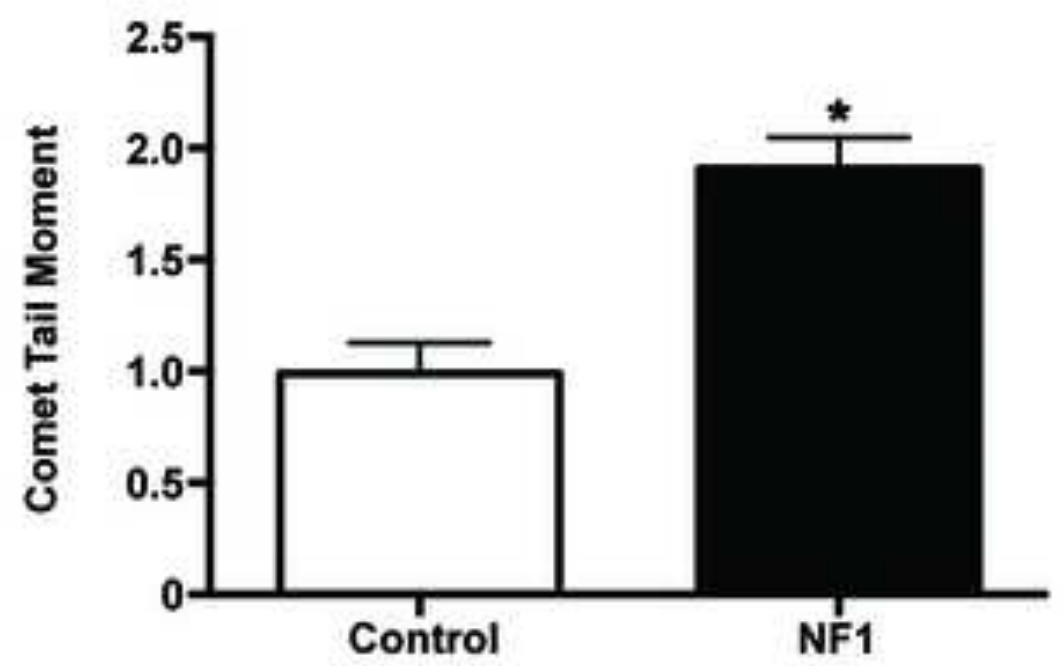

